\title{
Chasing the Caux Guiding Principles: Assessing their Legacy on Monitoring and Evaluation of Media Assistance
}

by

Irini Mavroudis

A thesis submitted to the Faculty of Graduate and Postdoctoral Affairs in partial fulfillment of the requirements for the degree of

\author{
Masters \\ of \\ Journalism
}

Carleton University

Ottawa, Ontario

(C) 2014, Irini Mavroudis 


\begin{abstract}
Post conflict societies offer an opportunity to reform and democratize media, as part of peace building and democratization. Since the 1990s, nongovernmental and intergovernmental organizations have provided assistance to local media in societies emerging from conflicts.

This thesis explores the concept of monitoring and evaluation of media assistance in conflict and post conflict settings. Only when properly assessing the assistance can we understand if and how it has an impact on peace building and democratization.

The thesis' case study is the Caux Conference, which assembled key actors and resulted in eight principles, the Caux Guiding Principles, providing advice on how to improve the sector. I interviewed six of the thirty participants to find out if the conference has had an impact and if the principles are being applied. The research suggests that the Caux Conference did not have a substantive direct impact, but that some of the principles have been applied.
\end{abstract}




\section{Acknowledgements}

I want to thank my academic adviser, Christopher Waddell for his guidance throughout the process, and the members of my committee who are taking time to read this thesis and give constructive criticism. I also want to thank Susan Abbott and Maureen Taylor, whose insights inspired the focus of this thesis; and the interviewees, without who this thesis would not have been possible. Finally, I want to thank my spouse, Doug for his support and understanding, and for cheering me on throughout this Master's Degree. 


\section{Table of Contents}

Abstract................................................................................................................................ ii

Acknowledgements .................................................................................................................................. iii

Table of Contents ............................................................................................................. iv

List of Tables ..................................................................................................................................... vii

Chapter 1: Introduction ........................................................................................................... 1

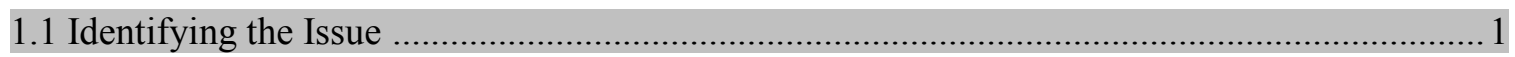

1.2 Role of Media Assistance in Democratization................................................................... 4

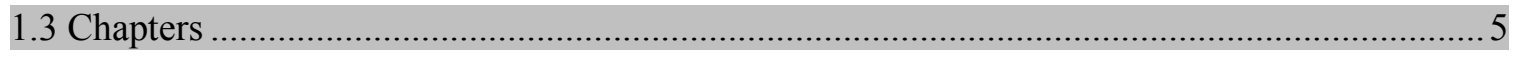

Chapter 2: Media Assistance and Interventions: Themes; Terminology; and

Background ..................................................................................................................

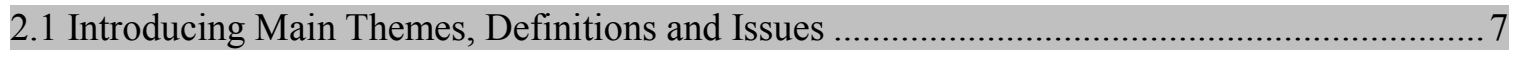

2.1.1 Definint Media Intervention ...............................................................................

2.1.2 Definint Media Assistance ……………………………………………………….. 9

2.2 Examining the Relationship between Media Assistance and Public Diplomacy ..................... 15

2.3 Introducing Press Freedom ……………………………………………………… 17

2.4 Historical Background of Media Internvention and Media Assistance …….........................2 20

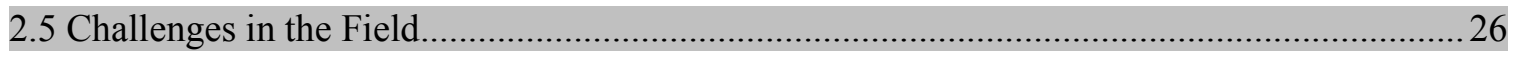

2.5.1 Challenges of the Media in Post Conflict Settings ……………………………………...2

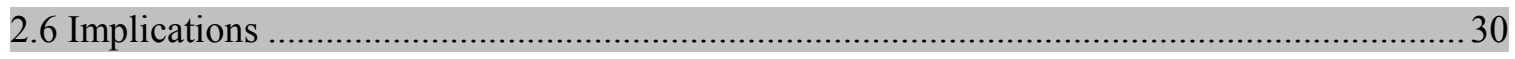

Chapter 3: Monitoring and Evaluating Media Assistance: Indicators and Indices . 35

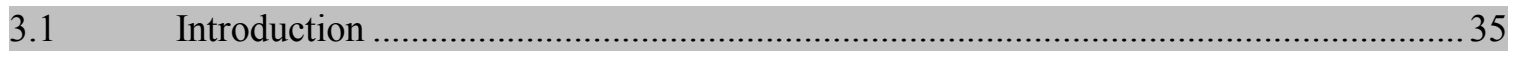

3.2 Defining Monitoring and Evaluation................................................................. 36

3.3 Indicators: Definitions and Limitations............................................................ 38 


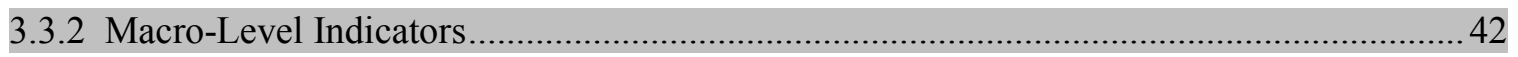

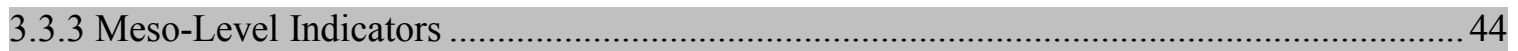

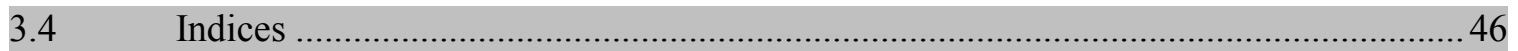

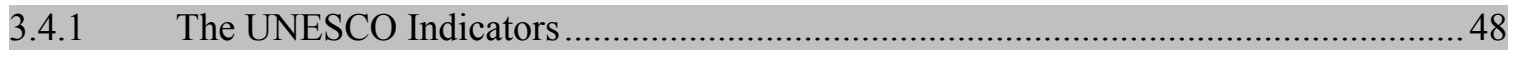

3.4.2 The Media Sustainability Index...................................................................... 51

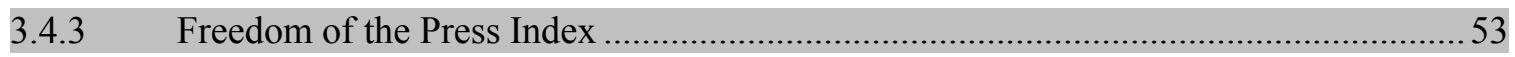

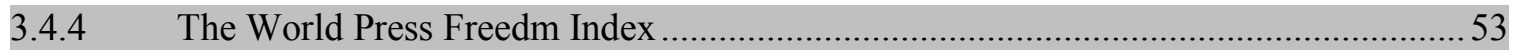

3.4.5 The African Media Barometer........................................................................... 54

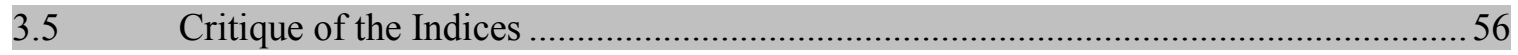

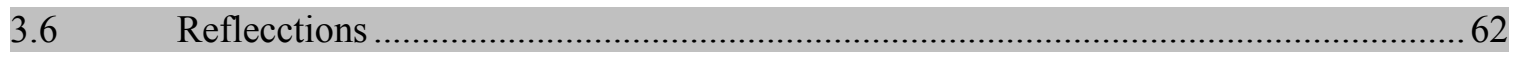

\section{Chapter 4: Challenges of Monitoring and Evaluating Media Assistance in Conflict}

and Post Conflict Settings............................................................66

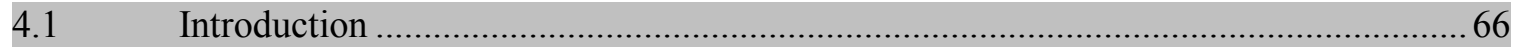

4.2 Specific Kinds of Media Assistance .................................................................... 67

4.3 General Challenges in Conflict and Post Conflict Settings ........................................69

4.4 Monitoring and Evaluation-Related Problems and Suggested Improvements ............. 73

4.4.1 The Donor-Practitioner Relationship....................................................................... 73

4.4.1.1 Encouraging Realistic Expectations …............................................................. 74

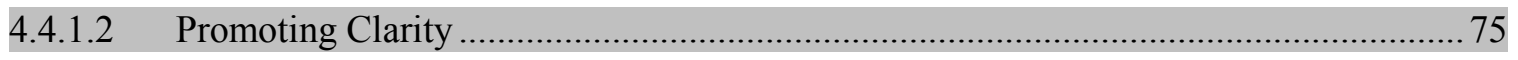

4.4.1.3 Conflict-Specific Approaches to Research Methods .............................................. 80

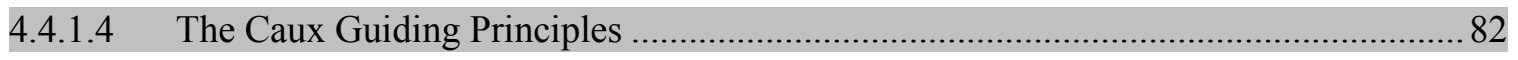

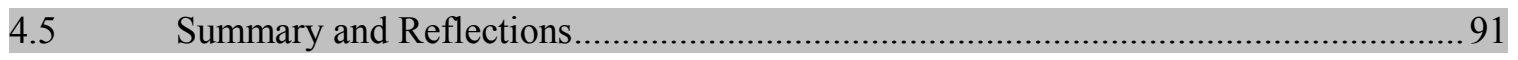

Chapter 5: The Caux Conference: Its Principles, Impacts and Legacy.............93

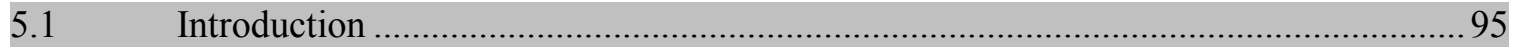


5.2 A Global Context to the Caux Conference …........................................................ 95

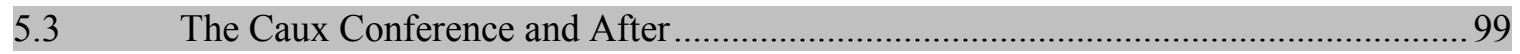

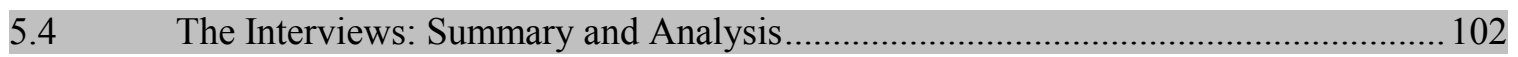

5.4.1 Are the Caux Guiding Principles adopted and applied? .......................................... 103

5.4.2 Do stakeholders regularly meet up and discuss best practices?............................ 108

5.4.3 Is there an established community of practice engaging in sharing and learning from

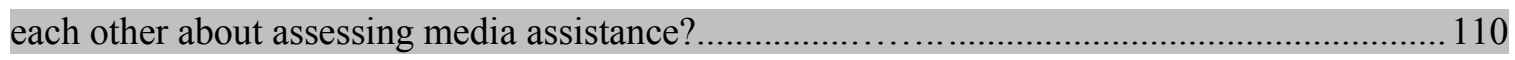

5.4.4 Are the donors engaged in a continuous dialogue with scholars and practitioners... 113

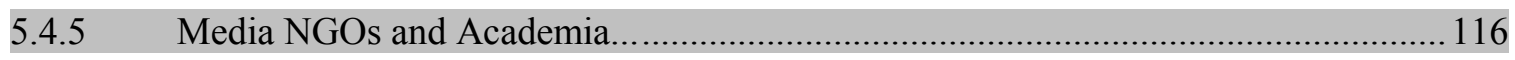

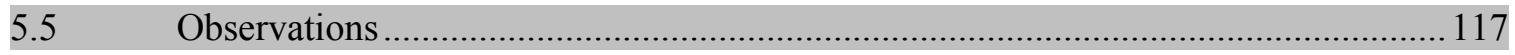

Chapter 6: Conclusion and Implications $\ldots . \ldots \ldots \ldots \ldots \ldots \ldots \ldots \ldots \ldots \ldots \ldots \ldots \ldots \ldots \ldots . . . . \ldots 121$

6.1 What is being done to professionalize the field? ................................................ 121

6.2 Have appropriate monitoring and evaluation frameworks and research instruments

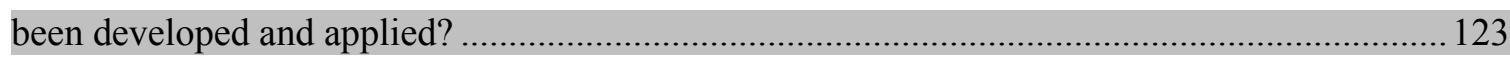

6.3 Have the Caux Guiding Principles Been Established as a Type of Guidelines and if so,

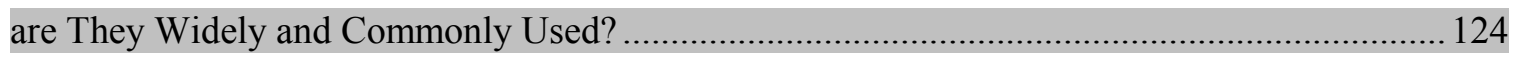

6.4 Is There a Consensus About What Indicators Are Most Appropriate to Measure Media

Assistance? Is There a Common Standard Being Used ....................................................... 124

6.5 Recommendations for Future Research...................................................... 125

Appendix A............................................................................................................................... 127

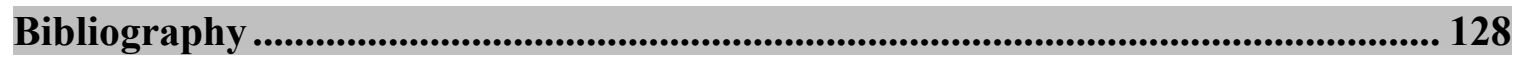




\section{List of Tables}

Table 1 Levels of media assistance as described by Monroe Price....................15

Table 2 Comparing Donors agencies' logical framework matrixes....................78

Table 3 List of Participating Organizations at the Caux Conference 2010............101 


\section{List of Appendices}

Appendix A Interview Questions

127 


\section{Introduction}

\subsection{Identifying the Issue}

What impact does media assistance have on democratization processes in post conflict societies? How would one even attempt to measure such an impact? These questions have been haunting me for a few years, ever since I talked to people working with press freedom issues during my travels in Sri Lanka and South Africa. When the time came to write a thesis, the questions resurfaced and I decided to make them the subject of my investigation. However, answering these questions turned out to be more complicated than I had imagined.

Post conflict societies offer a window of opportunity to reform and democratize media, as part of democratizing society. Since the early nineties, a multitude of NGOs and IGOs have provided programs and projects designed to assist countries emerging from conflict settings. The programs provide assistance in a variety of ways, from building infrastructure and radio stations, to providing education and training, to offering advice on legislation and financial models. As this branch of democracy assistance is growing, donors and policy makers are increasing their demands on media development organizations to thoroughly assess the programs to find out if they have an impact on democracy and peace building processes (Price et al., Arsenault et al.).

In December 2010, some of the key actors in media assistance, including nongovernmental organizations specifically involved in assisting media and communication sectors (media NGOs), intergovernmental organizations (IGOs) such as the UN, donors from the private and public sectors, academic researchers, monitoring and evaluation professionals, and private consultants, convened at a conference in Caux, 
Switzerland, to discuss experiences and challenges of assessing programs in conflict and post-conflict settings. What constitutes evidence, and how to measure the impact of media assistance on peace building and democratization processes were issues high on the conference agenda. A couple of key insights emerged: that interpretation of impacts and evidence varies among the stakeholders; and that there is no standardized way of measuring.

The Caux Conference lasted for five days and produced the Caux Guiding Principles; a set of eight principles that serve as a roadmap and concretely formulated advice, aimed at improving assessment methodology and practices, and building a community of practice, among other things. It was also an attempt from the media NGOs, engaged in designing and implementing of media assistance programs, to engage donors in a discussion about the challenges in the field and the western governments' and donors' unrealistic expectations of what the media NGOs can accomplish in terms of impact.

Considering the issues raised at Caux, Susan Abbott, former Associate Director of the Center for Global Communication Studies at the Annenberg School of Communication, and Maureen Taylor, the Gaylord Family Chair of Strategic Communication at the University of Oklahoma, suggest in a common article that there needs to be more collaboration between media development practitioners and academic researchers to collect and standardize the tools used, adapt them to what they are supposed to measure and evaluate, and generally professionalize the fields of assessment, in order to advance media development (266). 
Although recent progress has been made in the monitoring and evaluation of media assistance, especially in terms of developing and applying standardized tools, problematic gaps and challenges remain. What still needs to be done to further professionalize the field?

To start with, I am curious, in the three years since the publication of their article in 2011, and since the Caux Conference in 2010, whether the different stakeholders have pursued greater collaboration and whether the Caux Conference has had an impact. Therefore, in this thesis, I set out to explore the answers to the following questions: what is being done to professionalize the field?; have appropriate monitoring and evaluation frameworks and research instruments been developed and applied?; have the Caux Guiding Principles been established or accepted as guidelines and, if so, are they widely and commonly used?; is there a consensus about what indicators are most appropriate to measure media assistance?; and, is there a common standard being used?

The important role that assessment should play in improving media assistance is recognized by Arsenault, Himelfarb and Abbott: "Improving and expanding evaluation of current and future projects is essential because evaluation provides critical evidence that can inform future programs and better direct donors and policymakers in the judicious, economical allocation of funding and policy" (3).

The reason for studying the topic of discussion and collaboration between the different parties is that such cooperation has been identified as being of great importance for all parties involved (Abbott and Taylor). As Abbott and Taylor conclude: "More needs to be done collectively by researchers and practitioners, together, to think through the research framework and achieve better approaches and support systems for providing 
evidence of impact" (258). Their hope is that collaboration ultimately will contribute to the improvement of media assistance, and, thus, also to the processes of democratization and peace building.

\subsection{Role of Media Assistance in Democratization}

In order to gain a comprehensive understanding of the issues at hand, I conducted a critical literature review, covering the background and context of media assistance as part of democratization processes and the issue of how to measure impact of media assistance. These two fields, which partly overlap, provide insight into the goal and purpose of media assistance, as well as the issues of measuring and evaluating media assistance.

I conducted both primary and secondary research. The secondary research consisted of reviewing books, and articles found in academic journals, as well as reports and papers published by governmental bodies such as USAID, intergovernmental organizations such as UNESCO, and nongovernmental organizations such as Fondation Hirondelle and Internews. For my primary research, I conducted interviews with key informants from the media assistance community who participated in the Caux Conference. The interviews provided insight into whether the Caux Guiding Principles have been adopted, whether collaboration is established, and more.

As the field of media assistance has developed rapidly since the 1990s, and as the demands to monitor and evaluate programs and activities have only arisen during the past decade, there is very little academic research about monitoring and evaluating media assistance programs and projects. There is even less academic research about 
collaboration between academia and practitioners. This lack of academic research is both a limitation and an opportunity. It provides an opportunity for researchers to collect information and conduct original research. However, it is also limiting in terms of secondary material to refer to and build upon.

Another limitation in my research involves my choice of method: i.e. qualitative research in the form of key informant interviews. I am aware that a number of issues arise from this choice. For example, the key informants may not provide all the information asked for or needed; the information received during the interviews may not be objective; my questions may not be enough or properly designed to extract the relevant information; or the information extracted may not provide any new insights (Collier and Mahoney, King, Keohane and Verba).

\subsection{Chapters}

The first chapter introduces the definition of media assistance and related terminology such as media intervention, presents the historical background, and discusses the context of media assistance in conflict and post-conflict settings, and as a part of democratization.

The second chapter provides a discussion about how and what to measure when assessing media assistance. I will discuss the different definitions and ways of organizing indicators and indices. I will also go through the most commonly used indices, assessing their strengths and weaknesses, and identifying some of the academic critiques directed at them. 
Chapter three takes a closer look at the conflict and post-conflict societies, the challenges of operating in these settings, and why there is a need for specific tools to assess media assistance in such contexts. This chapter also introduces the Caux Conference and the Caux Guiding Principles.

The fourth and last chapter starts with providing a global context for the Caux Conference. However, it mainly contains the summary and analysis of the interviews conducted with some of the participants of the conference. Some answers to the guiding questions formulated in this introduction are presented in this chapter.

Finally, the concluding part of this thesis summarizes previous chapters, draws attention to important points and discoveries made, and answers all the questions posed above as completely as possible.

My goal is to shed some light on the challenges of assessing media interventions and media assistance in conflict and post conflict settings, and to determine if there has been an improvement of assessment methodology and practice through increased dialogue and collaboration between donors, media NGOs, academic researchers, and monitoring and evaluation professionals. It is hoped that the answers found, and the lessons learned, may contribute to the development of more effective media interventions, and improved media assistance, as well as to a better understanding of media assistance's role in peace building and democratization. 


\section{Media Assistance and Introductions: Themes; Terminology; and Background}

\subsection{Introducing main themes, definitions and issues}

Conflicts tend to have a transformative effect on the national media situated within the countries engaged in war. Local media exposed to civil wars, or conflict situations within a country, such as Afghanistan, Rwanda or Sudan, also go through transformation caused by the conflict dynamics. Media have often been used by different parties in a conflict as tools of propaganda, rather than as a public space for a free and fair assessment of politics and society. Hence, the core of the liberal notion of media and its role in society is altered in a conflict setting. As Marie-Soleil Frère expresses it: "Wars and conflicts generate significant threats to the media sector, as they create unfavourable economic conditions, turn reporters into propagandists and strengthen the control of information - on the side both of the public authorities and of the other belligerents" (14).

How then, after the conflict has ended, does the media claim, or reclaim, its place in a post-conflict setting? How can it be ensured that conflict structures and practices are replaced with reporting of fair and balanced information? Increasingly, attempts to establish media's place are made with external help from the international community, by way of assistance from different intergovernmental organizations (IGOs) such as UN bodies, and national donor agencies and non-governmental organizations (NGOs) engaged in the larger project of reconstruction and rehabilitation.

The academic literature tends to refer to this phenomenon either as "media intervention", or as "media assistance" (Kumar 2006, de Zeeuw and Kumar 2006, Price 2000, Price and Thompson 2002). There is a differentiation between the two concepts, 
but the boundary between them appears to be fluid. For the purposes of this thesis, I will define each concept, and treat them as distinct.

I will also discuss the concept of public diplomacy and how it is related to media intervention and media assistance, addressing the similarities, differences and risks. Including public diplomacy in the discussion is relevant, since sometimes donors are accused of promoting their foreign policy and influence over another nation's citizens instead of simply assisting the media sector of that nation to transform and redevelop.

Furthermore, the notion of press freedom is introduced, and that includes a summary of part of the academic discussion concerning the concept. Press freedom plays a pivotal role in the various concepts of media assistance and media development, especially the discussion concerning the press' freedom from specific entities in society: the state, private enterprise, the political or financial elite, or the influence of foreign power -- be it a government or private interest. Press freedom is also important in the discussion concerning how and what to measure, when media assistance impact is being measured -- a discussion that will occur in following chapters.

I will also examine the historical context of media intervention, as part of the Allied Forces occupation and reconstruction of Germany and Japan after the Second World War. The post-colonial context in Africa, in which authoritarian leaders used mass media as a tool of nation building, and the problems that arise from this will also be examined. Both perspectives provide a context to why scholars studying the phenomenon of media intervention and media assistance argue for a liberal pluralist model of the media sector, with economically independent media outlets as a prerequisite for democratization of post-conflict countries. 
My contextualization of the history of media assistance will explain how it is a part of both democracy assistance and media development, and how this can be problematic. This historical background will lead to a wider discussion of the major challenges in the field.

\subsection{Defining Media Intervention}

The issue of media intervention surfaced on the international agenda in the 1990s, after ethnic conflicts in countries like Rwanda, Cambodia, and Bosnia-Herzegovina. For example, Radio-Television Libre des Mille Collines' (RTLM) instrumental role in the incitement of the Rwandan genocide was a wake-up call to the international community and led to a recognition of the need for preventative interventions to stop propagandistic use of media in conflict settings (Price 2).

Scholars have coined the term information intervention "to comprise the extensive external management, manipulation or seizure of information space in conflict zones" (Price and Thompson 8). Hence, the term is not absolute; it gathers a number of practices and circumstances in a flexible definition (Price and Thompson 8). Jamie F. Metzl, who introduced the term, proposes that the definition frames a variety of strategies to be used as a response to "'misuse of mass communication', especially where there is a potential for mass violation of human rights" (qtd. in Price and Thompson 8). In this thesis media intervention and information intervention are used interchangeably, except where otherwise mentioned and explained. However, where necessary, I will indicate a distinction. 
The mandate to intervene in a foreign country's media sector is held by major actors in the international community, and is often part of a larger and more extensive international operation in a nation experiencing conflict: "information intervention would be a way to broaden the range of intermediary opportunities available to the UN, NATO or the United States as it engaged in peace keeping measures in ethnic and other conflicts" (Price 2). ${ }^{1}$

Two different approaches emerged in the wake of peacekeeping missions that took place in the 1990s (Price 2). One argued for intergovernmental organizations (IGOs) to set up media outlets outside of the existing local media structures to provide neutral and peace-oriented information (Price 2). The other believed in "strengthening local, indigenous media outlets, particularly those that strike a new voice, in the hopes of building a new sphere, a civil society, and the long-term machinery for peace and reconstruction" (Price 2). According to Price and Thompson, the first approach was more popular with IGOs, and the second was more popular with NGOs (Price 2).

Price and Thompson advise to take into consideration that different situations may demand different types of interventions, for example, if the nation is in a pre-conflict, a mid-conflict or a post-conflict state (2002). Hence, the two approaches do not necessarily have to be at odds with one another. Rather they may serve to complement each other.

\footnotetext{
${ }^{1}$ Since the end of the Cold War, the majority of conflicts have been civil wars, with
} strong elements of ethnic and religious strife (Price and Thompson 2002). 


\subsection{Defining Media Assistance}

Media assistance is a term applied to the part of development that targets the media sector of certain countries. Monroe Price, media law and policy scholar and director of the Annenberg School of Communication at the University of Pennsylvania, places media assistance in the development sector, as a field that emerged in the post Cold War era of 1980s and 1990s, and calls it "media aid" ("Mapping Media Assistance" 1). According to Price, media assistance was originally "minor donations of equipment and training tours for journalists" but has now changed into "long-term, multi-facetted projects with multi-million dollar budgets" ("Mapping Media Assistance” 1).

Media assistance can be seen as part of different categories of "aid", or as part of different contexts. For example, it can be placed in a larger development context, or within a smaller democracy-building context. Price recognizes that media assistance programs fall under a variety of categories such as "governance, civil society, democratization, or similar departments" or even "under the umbrella of humanitarian assistance "(“Mapping Media Assistance” 1). In most of these contexts or categories, independent media and press freedom are in focus, both of which I will address at a later stage in this thesis.

Regardless of the context, media assistance consists of different methods aiming either to strengthen an indigenous media sector or to train journalists. Price defines them as follows:

Media assistance primarily takes the form of journalism training, direct support to news organizations, efforts to aid media law reform, support for professional journalism and broadcast associations, support for developing 
financial sustainability of media outlets, and initiatives designed to transcend national, religious or ethnic barriers in the media. ("Mapping Media Assistance" 2)

According to Dutch conflict research scholar Jeroen De Zeeuw and American senior social scientist Krishna Kumar, media assistance is a key area of democracy development, together with human rights assistance, political party development and post-conflict elections (vii). They argue that, "the promotion of responsible journalism through competent human rights-based media development are among the best results of international assistance in democracy promotion" (viii). On this view, media assistance seems to be a concept sprung from and connected to democracy assistance.

Kumar and de Zeeuw situate media assistance as part of a wave of democracy assistance launched in the early 1990s (9). It was during a period when "democracy programming evolved in response to challenges faced in individual countries", and, therefore the international donor community was neither coherent, nor coordinated, (de Zeeuw and Kumar 9). Democracy assistance initially meant electoral assistance, with the extent of involvement differing from one country to another (de Zeeuw and Kumar 9). However, it became apparent that human rights monitoring and legal assistance, as well as media assistance, were needed.

According to de Zeeuw and Kumar, "the international community failed to devote adequate attention to the media in the early 1990s. It gave only limited media assistance to countries such as El Salvador, Cambodia, Ethiopia, Mozambique and Nicaragua" (11). 
Bosnia-Herzegovina, however, marked a turning point concerning how the international community practiced media assistance, largely due to the nature of the conflict and the way in which local media were used by political elites to mobilize the population according to ethnic divisions. The international community of donors and intergovernmental organizations designed innovative media programs "that involved assistance to non-state media entities, training of journalists, legal and regulatory reforms, and technical assistance to make the independent media economically viable and sustainable" (de Zeeuw and Kumar 11).

The international donor community regards support for the independent media sector as key, since a diverse media sector is believed to be "essential for democracy, promoting transparency and accountability in public affairs, providing a voice for the people, and encouraging free and unfettered political debate" (de Zeeuw and Kumar 11). This multi-facetted approach to media assistance has since become a common mode of operation, according to de Zeeuw and Kumar, and there is now "a broad consensus among international policy makers that independent and responsible media should be supported in post-conflict societies to promote democracy and pluralism while defusing political tensions" (11-12).

The US has been and still is a major donor engaged in democracy assistance. It is worth noting that until the 1990s, media assistance was mainly funded and administered by the United States Information Agency (USIA)/United States Information Service (USIS) or the National Endowment for Democracy (Mapping Media Assistance 6). As of the fall of 1999, the responsibility was moved to the US Department of State, to the Bureau of Education and Cultural Affairs (ECA) (Mapping Media Assistance 6). USAID 
became the major donor of contracts or grants through the implementation of the Freedom Support Act. This shift is noteworthy in this context because it may be interpreted as a change in perspective, shifting from one of "media intervention" to "media assistance". As Price argues, "The shift from USIA to USAID is significant both to amount, management style, notion of mission, and relationship to development and democracy" (Mapping Media Assistance 6).

The structure and purpose of media assistance is complex and involves a network of different actors. These actors vary in size and power, and operate on different levels. Some specialize in a certain type of media assistance, such as training or legal advice, while others focus on a geographic area and engage through a more multi-facetted program in the area, or many different projects through the region.

Typically, the larger governmental organizations such as USA Development Agency or, or intergovernmental organizations such the European Commission, fund smaller private organizations or NGOs who have more specific projects. Monroe Price constructed a schema to show the structure of and relationship of various donors and actors in the field of media assistance (see figure 1) (Mapping Media Assistance 5). This figure helps to understand some of the challenges and issues that appear in the field, which will be discussed further on. 
FIGURE 1

Donors and Actors

Donors \& Donor/Implementers

- Governmental Organizations (EC, USAID, DFID, SIDA, etc)

- International Governmental Organizations (UNESCO, OSCE, CoE, World Bank, EBRD)

- Foundations (OSI, Friedrich Ebert Stiftung, Freedom Forum, etc)

- International Industry Associations (EBU)

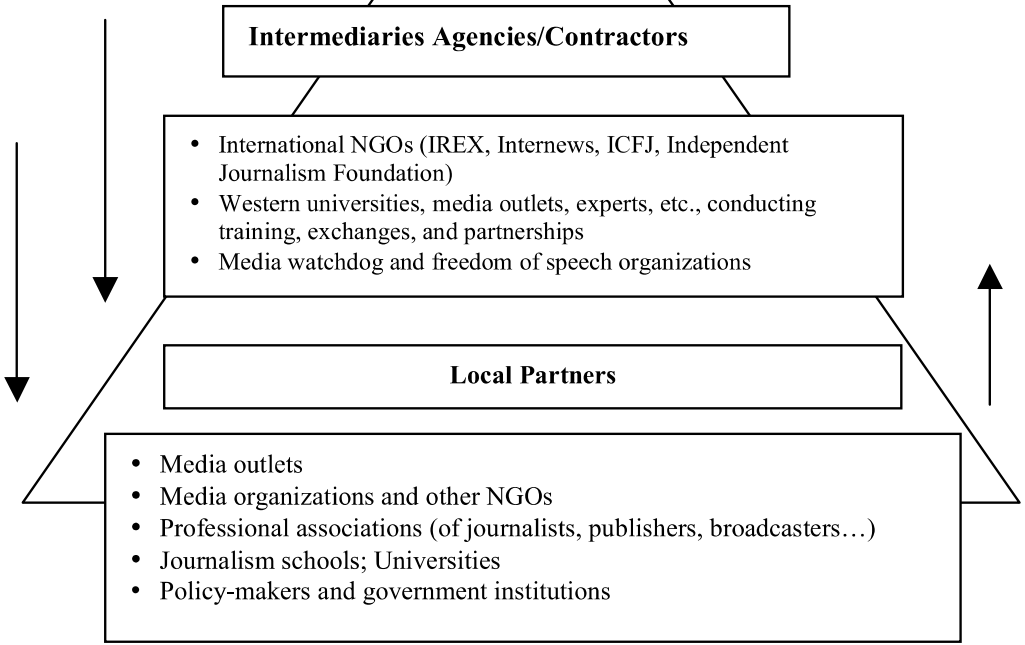

Table 1.The levels of media assistance as described by Monroe Price (Mapping Media Assistance 5).

For the purpose of this thesis, I will not focus on a specific donor or organization, but rather discuss the relationship between the donors and intermediary agencies in general. As will become apparent in chapters four and five, my case study, the Caux process, mainly focuses on the intermediary level of agencies and contractors and their relationship with academia and donors. 


\subsection{Examining the Relationship Between Media Assistance and Public Diplomacy}

Price and Thompson raise the issue that the term 'media intervention' "implies two kinds of activity that should be distinguished conceptually and practically. One is public diplomacy, and the other is "media development activity, which, in various ways aims to assist in building a democratic media sphere" (8).

Like Price and Thompson, Krishna Kumar argues that the two concepts have different strategies and overall objectives (2). While "public diplomacy seeks to promote a country's foreign policy interests by informing and influencing the foreign audience", media assistance aims "to develop and strengthen the indigenous capacity for free and unfettered flow of news and information, bolstering democratic institutions and culture" (Kumar 2,3).

However, Kumar also recognizes that there is a certain ambiguity between the two that may be problematic. He brings attention to two recent cases of public diplomacy that may be confused as media assistance: one, where Voice of America launched a Farsi channel targeting Iran, with the purpose of providing a more balanced image of the United States; two, advertisement in Middle Eastern mass media funded by the US State Department, portraying freedom of religion in the United States (Kumar 3). According to Kumar, the examples show how public diplomacy can use media for its benefits, in this case provide positive images of the United States in regions that are politically hostile to America (3). Furthermore, he recognizes how these methods "could possibly pave the way for the eventual emergence of free media outlets in the region", but he argues that they should not be mistaken for media assistance (3). 
The risk with media assistance "being used as a tool of public diplomacy" is that it "creates false expectations in donor countries and genuine apprehensions in recipient nations" (Kumar 3). The false expectations may include that the media-assisted channels in a recipient nation should report uncritically on the donor country's policies, or even promote them (Kumar 4). The genuine apprehension of recipient nations may include increasing scepticism regarding the donor country's intentions (Kumar 4). Kumar warns that the result of this blurring of public diplomacy and media assistance through development agencies may well lead to an official refusal of certain nations to admit media assistance "because they [officials] might view it as a foreign effort to buy influence and manipulate their media sector" (4).

Kumar understands the apprehension, and explains it with the historical connection between media assistance, media intervention and public diplomacy. He mentions the example of Voice of America and Radio Free Europe and how their mission was to target Eastern European countries during the Cold War (4). He also recognizes that the two can "still complement and reinforce each other" and mentions Serbia after the Balkan War as an example (4). In conclusion, although Kumar identifies that blurring the two concepts may be problematic, he also believes that as two complementary strategies, they may serve to build an independent media sector in transitional or authoritarian societies, which in turn serves to make these societies more free and democratic (2006). 


\subsection{Introducing Press freedom}

Press freedom is a concept widely discussed in both the fields of communication and political science (Becker and Vlad 24). The concept, as such, is intrinsically linked to the concept of democracy, as a way to measure the level of democracy in a society. Already the Hutchins Commission's report “A Free and Responsible Press” (1947) discussed the relationship between the free press and democracy. "The 133-page report contends that the press is free for the purpose of serving democracy; a press that shirks its democratic duties will lose its freedom. The report calls on the press to improve itself in the name of morality, democracy, and self-preservation" (Bates 1). However, if press freedom entails only the freedom of government or from corporations too, is widely discussed both within academia and elsewhere.

Siebert, Peterson and Schramm (1956) define press freedom in relation to freedom of government. Siebert et al.'s four normative theories of the media became pillars in journalism studies, communication studies and political science (Becker and Vlad 24). The four theories are: the authoritarian, where the press and its purpose is government controlled by different means; the Soviet Communist, which was the Cold War version of the authoritarian theory; the libertarian - where the press is seen as a commercial enterprise free from any control but the owners; and the social responsibility theory, in which the press is assigned an obligation to inform the citizens and enlighten the public as well as being free from government and serving as a watchdog (Siebert, Peterson and Schramm).

Hallin and Mancini criticize Siebert et al.'s theories for “having stalked the landscape of media studies like a horror movie zombie for decades" and developed and 
adapted their theories to a post Cold War setting, first by looking at Western European "capitalist democracies" and then expanding their analysis to include other political systems and nations beyond the "West" (Hallin and Mancini 10).

Their three media system models are: the liberal model, which "is characterized by a relative dominance of market mechanisms and of commercial media"; the democratic corporatist model, which is shaped by "a historical coexistence of commercial media and media tied to organized social and political groups"; and the polarized pluralist model which is defined by media's relationship to party politics, its "weaker historical development of commercial media, and a strong role of the state" (Hallin and Mancini 11).

Their models are developed using a systemic approach, and have been criticized for this. For example, Rozumilowicz suggests that a systemic analysis using the three models is too limited, and that a process-based approach should be used to open up the concept in order to better understand the complex relationship between media, press freedom and democratization (Price, Rozumilovicz and Verhulst 2002). Her approach suggests seeing the relationship between media, press freedom and democratization as a process rather than just as systems. She also argues that free and independent media "are not good in themselves, but only in as much as they support other, more intrinsic values and goals (that is democracy, a particular economic structure, greater cultural understanding, general human development and so on)" (Price, Rozumilovicz and Verhulst 12).

Furthermore, she emphasizes that in order for the press to be free, it must be free from all entities in society, governmental and corporate, as well as free from dominant 
social groups that may have an interest in using media to shape public opinion (Price, Rozumilovicz and Verhulst 12, Vlad and Becker 26). In order to maintain this freedom, society needs to provide the right conditions and be "supported by a nation's legal, institutional economic and social-cultural systems" (Price, Rozumilovicz and Verhulst 12, Vlad and Becker 25).

Weaver includes non-governmental entities in his model and looks at the environment in which mass media operates. In short, he focuses on three aspects of press freedom: "the relative absence of government restrains on the media, the relative absence of nongovernmental restrains, and the existence of conditions to ensure the dissemination of diverse ideas and opinions to large audiences" (Vlad and Becker 24,25). Political theorist and media critic Noam Chomsky on the other hand, includes private interests in his definition of the "elite" that tend to dominate media (Herman and Chomsky 2). Using his "propaganda model", he argues that corporations can exert similar or the same kinds of control and censorship as an oppressive government (Herman and Chomsky 2).

Media economics scholar Robert Picard recognized that press freedom can be divided into concepts of positive and negative, where positive press freedom is the freedom of individuals to use and access the media, while negative press freedom is "the absence of legal controls, such as censorship" (Picard qtd. in Vlad and Becker 25).

In this thesis, press freedom will mainly be discussed in relationship to monitoring and evaluation: how press freedom is measured, the main methods used for measuring, and whether or not the existing press freedom indices are adequate to measure the success of media assistance. 


\subsection{Historical Background of Media Intervention and Media Assistance}

The relationship between local media and the international community in postconflict settings was largely unexamined by scholars before 2002 (Price and Thompson 1). Hence, the authors who have chosen to approach the subject are a mix of scholars and practitioners, and come from a variety of fields, such as international law, international development, democracy building and governance, communications, and journalism. Therefore, to better understand where and when the perceived need for media intervention arises, let us first examine the historical background of mass media structures in a democratization context.

Monroe E. Price and Mark Thompson trace media intervention to the end of World War II, when the Allied Forces aimed at completely transforming the media sectors of Germany and Japan, and other allies (2). The goal was to eliminate war propaganda machineries, including those promoting blatant racial ideology and nationalism. The Allied Control Council was in charge and used "overwhelming media control and the transformation of press and broadcasting" in order "to advance democratization" (Price and Thompson 4).

Different countries were responsible for different "zones" of the new Germany, and hence, they organized the media sectors according to different models. For example, a French radio network was set up in Baden-Baden copying the French model, Britain was in charge of the Northwest German Radio and modelled it after the BBC, and the US organized separate networks in each of the German provinces (Price and Thompson 4). What they all had in common was the aim to create media sectors independent and 
separate from the locus of power politics and its possible influence. According to Price and Thompson, "these efforts spawned a variety of approaches", approaches that became "the prototypes of post-conflict information management" (4).

Decentralization and the division of main media outlets were part of a conscious strategy to break down old national structures and keep Nazi ideology from resurfacing, all according to the Potsdam Agreement of August 1945 (Price and Thompson 5). "Denazification, meaning the removal of Nazis from public life and elimination of the influence of Nazism, was a primary responsibility of the Occupiers" (Price and Thompson 4). As a result, efforts were made to "denazify" and restructure the entire public sphere in order to create a new base for democratic institutions to grow. This encompassed publishing houses and bookstores, as well as theatre and film production not just the media sector. They were all set under "Military Government supervision" (Price and Thompson 5). Radio was the medium that stayed the longest under the supervision of the Allied Forces, since it played such a crucial role in war instigation (Price and Thompson 5).

Similarly, Japan also experienced a thorough ‘clean-up' of “all elements of militarism and nationalism from the media" (Price and Thompson 5). To accomplish the mission to extinguish these elements and establish the "freedom of speech and press", the Allied General Headquarters put official censors in place (Price and Thompson 5). Furthermore, the news had to be "faithful to the policies of the allied powers and refrain from sceptical criticism of the allied forces" (Price and Thompson 5). This included any mentioning of the U.S. bombings of Hiroshima and Nagasaki. 
Price and Thompson's historical account of the post-WWII information intervention shows that it was, in fact, part of a military occupation, using a military apparatus to annihilate an old order, and impose a new framework for new ideas, practices and institutions to be established. According to Price and Thompson, this strict regime and practice, accompanied by "a legal regime that transformed the structures, management and content of existing media outlets", was necessary to reach the goals of establishing democracy in the particular context and scale of post-WWII (5). Their account of the information intervention in Japan also shows the link between media intervention and public diplomacy. Comparing and contrasting with today's information interventions, they state that they "lack the clarity of authority and purpose that the Allied military victory provided in 1945" (Price and Thompson 5).

Reading material concerning media interventions since the 1990s demonstrates that there has not been an intervention of the scope or scale like the interventions of post WWII. It may be that as a result, the context and the needs of more contemporary interventions have been somewhat different. The historical context has changed, as have the dynamics of the international political arena. In spite of these differences, however, Price and Thompson argue that what is practised today in the fields of media intervention, as well as media assistance and public diplomacy in post-conflict or development contexts, originates in the approaches first developed by the Allied Forces in the wake of WWII.

While Price and Thompson approach the subject of media intervention from a post-conflict perspective, others approach it from a nation-building perspective in a 
development context. What they have in common is the view of it being a part of assisting the process of establishing and developing democracy.

Goran Hyden and Michael Leslie place the development of national local media within the framework of modernization, and focus on emerging post-colonial African countries (2002). Summarizing communication research from the late 1950s and early 1960s, they find that mass media was seen as a key element in national development and nation building (Hyden and Leslie 2002).

Stanford scholar Wilbur Schramm emerges as particularly influential in pursuing this line of thought (Hyden and Leslie 3). According to Hyden and Leslie, Schramm argued that national governments should "harness the power of the mass media in promoting national development", and that his research convinced the United States Agency for International Development, the Peace Corps, and the UN, among others, of the necessity for policies and programming that corresponded to this idea (4). The result was "a one-way operation", where "people were being spoken to", and democracy was seen "as a by-product of the improvement of socio-economic conditions" rather than a goal in and of itself (Hyden and Leslie 4,5).

Hyden and Leslie further argue that Schramm's "relatively linear and simple development model" was too "optimistic", and that development needs a more complex analysis and approach (4). By situating Schramm as a representative of modernization, they provide a context to his ideology, and the "technical or instrumentalist rationality which guided modernization" and development at the time, with the United States as the main promoter (Hyden and Leslie 5). 
An important issue raised by Hyden and Leslie's historical analysis, is how modernization resulted in governments taking power over mass media to further their interests, and then relieving themselves "from responsibility of their actions" (21). They argue that the mass media in post-colonial African countries were mainly "propagandist rather than informational", and that this was due to government ownership or control (10).

The observation of governments trying to control mass media and the negative consequences of this practise has support in communication theory. For example, Hackett and Gruneau argue that governments have acted to limit free speech "in the name of national security, public morality, or social order", while the underlying reasons in fact was "to stifle information or viewpoints that could embarrass the authorities or provoke political opposition” (171).

By the 1980s, the political and ideological situation shifted, however, and governments were no longer seen as the sole engine of national development. Instead voices were raised in favour of privatization of the media. This lead to changes in the media sectors in the 1990s, when many African countries passed legislation concerning press freedom, which in turn led to a more open media landscape (Hyden and Leslie 11).

Hyden and Leslie argue for the positive impact of privately owned media in the process of democratization in African countries (12). They believe that privately owned media serve two functions: first, as a watchdog towards government and the extended political realm; and second, "to help foster a discursive public realm, in which issues of national and local concern are ventilated in an open and free fashion" (12). 
It is worth noting that Hyden and Leslie do not scrutinize the risks of private ownership, such as influencing or censoring of content by political or commercial forces, or the tendencies of private media to push consumerist culture and practice on its readers, reducing them to consumers rather than raising them to be engaged citizens.

They also fail to mention how the corporate elites are able to shape and control the content in privately owned media, through pressure or ownership. Noam Chomsky and Edward Herman show in their propaganda model how the "money and power are able to filter out the news fit to print, marginalize dissent, and allow the government and private interests to get their message across to the public" (2). For example, they argue size and concentration of ownership, as well as having advertising as a primary source of income, serve as effective filters. Robert Hackett and Richard Gruneau support the idea that different forces practice the act of conscious suppression in the media market system, including governments, media corporations and interest groups alike $(25,26)$.

Chomsky and Herman, and Hackett and Gruneau criticize media ownership in already established democracies. In the vulnerable setting of a post-conflict society, the discussion of ownership is even more relevant in relation to the developing democracy. Hence, assisting in the establishment of independent media outlets that can inform the citizens and serve as watchdogs of the elite is one of the major goals of media assistance.

A post-conflict media sector needs all the support it can get to establish a healthy political economy and a legal framework that supports the factors that keeps it healthy and independent. However, as we will see further on in this thesis, there is plenty of critique to how this is presently done. 


\subsection{Challenges in the field}

In examining the literature on media intervention and media assistance in postconflict societies, several problems surface. They are related to different aspects of peace building, of democratization, and of how the international donor community functions. This section examines the problems of media sectors in post-conflict settings represented by challenges faced by structure and ownership; the issues that stem from the international donor community's assistance; and the inherent confusion regarding the nature and underlying purposes of media assistance, including timing, type, targeted levels and sustainability.

\subsection{Challenges of the Media in Post-Conflict Settings}

Marie-Soleil Frère identifies nine main obstacles facing media sectors in developing countries: media without enterprise, the 'dangerous liaisons' between media and politics, the government's public media, the media's limited scope and the information blackout, attacks on the press, the regulatory authorities' weakness and bias, obstacles to information access, political candidates' campaign strategies, and confusion between communication and information (2011).

Frère argues that even when there have been efforts to establish a pluralist media environment, in many cases, legal and regulatory frameworks have done little to regulate ownership structures. The result is a superficial "pluralism", with politicians and political parties standing as owners of private radio stations and newspapers. In real terms this 
means a polarized and partisan media that does not necessarily report in a socially responsible way.

A partisan and polarized media can be extra harmful in a post-conflict context during elections. Elections provide the arena for actors that may have recently been fighting each other in war, to meet in a peaceful manner as political parties and opponents. A free press and independent and diverse media are key to free and fair elections, but if only "superficially" pluralist and free, they can also pose a great threat to a budding democracy. Therefore, a regulated media sector may be of great importance. Frère makes the case that although everyone involved in the public sphere and the process of free and fair elections should be able to express themselves freely, there needs to be a regulatory framework, both legal, such as press laws, and ethical such as codes of conduct, according to which media and journalists operate (4).

There does not seem to be a uniform approach to media assistance in post-conflict countries. Each context is different and needs support to find its own specific set of tailored solutions. Although issues may arise that are context and country specific, they are not always a consequence of local shortcomings. Sometimes those who provide the funding for assistance, the international community of donors, are the actual cause of a problem (Frère, Price and Thompson, and Kumar and de Zeeuw).

Kumar and de Zeeuw found that when the international community contributes to one sector, say, holding elections, but fails to contribute to another, such as institution building, the whole project of establishing peace and democracy runs the risk of failing (14). For example, in Cambodia, the United Nations Transitional Authority in Cambodia (UNTAC) organized elections, but did not assist in establishing a proper electoral 
administration (Kumar and de Zeeuw 14). Instead, foreign firms were hired to do the administration, with the result that no records were kept, no local knowledge was established of how to administer elections, and there were no institutions to hold and proliferate the practice or knowledge needed for future elections (Kumar and de Zeeuw 15).

Another example of donor community blunders is the cases of insensitivity to the local context. In Bosnia-Herzegovina for example, a setting plagued by ethnic conflict and hate speech, foreign media consultants without knowledge of the local context or languages were contracted to train local journalists in new methods and ethics (Kumar and de Zeeuw 15). The local reporters showed little interest in interacting with these consultants and change only took place after "international media NGOs invested in expanding training capacities within local institutions and pushed for other reforms" (Kumar and de Zeeuw 15).

Kumar and de Zeeuw identify a number of factors causing the blunders. Time, is one, funding requirements another, short-term commitment and lack of donor coordination yet others (Kumar and de Zeeuw 15). Donor agencies follow their countries' political policies, have limited funding, and adhere to strict rules and guidelines (Kumar and de Zeeuw 15). There is also the issue regarding what strategy a specific donor country has, political pressure or assistance (Kumar and de Zeeuw 15). Kumar and de Zeeuw argue for a combination of factors in order for democratization to be efficient, and are critical at the international community for preferring to practice solely "economic assistance" in many cases. 
Price and Thompson raise the problem that donor countries tend to regard media intervention as a 'soft' issue, and therefore may underestimate the power of the local media at the time of an international peace operation (13). Since local authorities see media as a way to control public opinion, they may be reluctant to let go of this power, especially as it can be used to hinder certain aspects of international peace operations (Price and Thompson 14). In case of disagreement with the international community, local governments, generals or warlords may use local media to "undermine public support for a mission by distorting public perception of international objectives" (Price and Thompson 13). Therefore, the international community needs consent from the local government for the interventions to have a chance to be successful. However, reforming the media sector may still be both challenging and ultimately fail, as has happened in both the Balkans and Africa, Price and Thompson argue (14).

As noted, reforming and restructuring the whole media sector in a country has proved to be a challenge, and the international community often opts for interventions of a smaller scale, such as introducing alternative and independent radio channels run by local staff. When investigating the situation of the different media sectors in post-conflict Central Africa, Frère found that the only media outlets able to keep good quality reporting, stay out of political influence, and reach their audiences at most times, were those funded or set up by the international community.

Frère recognizes the importance of these media outlets, but is critical. She does not believe they are a sustainable solution, and questions what will happen after the Western donors withdraw. The media outlets risk losing their ability to sustain a high standard of reporting as well as their neutral positions, depending on who takes over the 
ownership and financial responsibility. She argues that this type of funding "raises the issue of both sustainability and editorial discretion" (239).

\subsection{Implications}

Despite the prevalent criticism by scholars such as Chomsky, Hackett, Gruneau and McChesney of private ownership, ownership concentration, and market-driven interests, scholars linked to democratization and peace building in post-conflict settings, seem to advocate ideas of private ownership and market-driven journalism, thus having a classic liberalist approach rather than a social responsibility approach. There seem to be viable reasons for this viewpoint, considering the inherited structures and power dynamics of either authoritarian rule or conflict. In such environments, where warlords, generals or dictators have appropriated the media sector in order to spur ethnic or religious conflict, the establishment of independent media and a self-sufficient and regulated sector is imperative.

For example, Frère argues for the importance of funding, and makes a compelling case for independently funded media. The identified "obstacles" of media trying to cover elections in post-conflict societies are mostly a combination of limited funding and power politics inherited from either an authoritarian past or of conflict dynamics, or both. The result limits journalists' possibility to practice free, fair and balanced reporting.

While Frère bases her argument on observations of history and present reality in Central Africa, De Zeeuw and de Goor base theirs on the idea of media's role in a liberal democracy. They argue, that, "an independent and diverse media cannot be overemphasized for promoting democracy in post conflict societies" (286). They firmly 
believe, that "a genuinely pluralist political system cannot exist without a free flow of information and a 'marketplace of ideas"' (286). They also refer to the consensus that exists among development theorists that economic growth and media freedom are intertwined (286). However, only when reading the end notes does one find out that these particular development theorists work for the World Bank; a circumstance that, may affect their objectivity and credibility regarding that particular argument.

Frère's argument is more compelling, that a healthy political economy of the media can be acquired through a combination of measures that include taxpayers' money as a model for funding public media, media outlets pooling resources, and the option of donor funding - but during specific circumstances and in a sustainable model (Frère 256).

How, then, to ensure that conflict practices are replaced with fair and balanced reporting? As mentioned above, a combination of different funding models is an important prerequisite, as are legal and regulatory institutions independent from political and financial powers (Frère 256). Training and education of journalists is necessary, as are implemented and internalized codes of conduct within the journalism community. The only chance for a socially responsible media to exist and to stay neutral from influence in any societal setting may be if the political economy of the media sector is healthy, and a proper legal framework is implemented in a fair way.

Frère's suggested solution resembles discussions of the future of funding public media in Canada, the US and Europe. Questions of ownership concentration and how they affect the quality of the content are highly relevant even in countries not in conflict. 
However, in a post-conflict setting the problems stemming from a weak political economy of the media sector are exacerbated.

How then, in the aftermath of a conflict, does the media sector reclaim its proper place in society within specific post-conflict environments? As noted in this chapter, every context requires different solutions. However, donor countries' policies and resources tend to dictate the type, timeframe and amount of money the media assistance will entail. Because of donor shortsightedness, the result is often short-term engagement, and lack of sustainable strategies. Part of the reason for this perspective, seems to be that the media assistance projects are oftentimes the answers to needs defined by the donor community, rather than by the actors in the local media sector. An important part of solving these challenges in a sustainable manner may be to allow the media themselves to participate in defining the problems and possible solutions. Frère makes an interesting observation, that when under the proper conditions, "journalists in Central Africa possess the capacity, the motivation and the courage in a highly insecure environment, to report professionally and to play their part in the electoral process" (Frère 239,242).

Media assistance is constantly evolving, including the efforts to define the problems and find the solutions. Until recently, the intermediary agencies have been designing and implementing projects and programs according to donor instructions, without any major pressure to show their impact on democratic development. However, with a rising trend among donors to ask for results, even in the more complicated practise of democracy building is experiencing the increase in pressure. The spotlight has turned from the work on the ground to the middleman, and mid-level agencies are developing methods and tools to show that their work matters. Accountability and transparency - 
buzz words of democratization, are now being demanded from the democracy designers and builders themselves.

This recent trend brings its own challenges to the table. Some of them are connected to the already existing challenges in the field of media assistance mentioned earlier: of ownership, timing, type of assistance, targeted levels, scale, sustainability, and so on. Others are connected to the methods and tools of measurement, which were once developed in a certain context, but are now used beyond their original purpose. The next chapter will focus on how to measure and evaluate media assistance, and look at the issues arising in this related field. 


\section{Monitoring and Evaluating Media Assistance: Indicators and Indices}

\subsection{Introduction}

As discussed in the previous chapter, media assistance and media intervention have existed in various forms and contexts since the Second World War. However, there is little academic discussion about implementers having to prove the impact or effect of various interventions and assistance. Not until the past 20 years has there been an interest in measuring and evaluating media assistance (Alcorn et al. 3). This is surprising, given that the USAID started measuring aid effectiveness in quantitative terms as early as the 1970s (Lamay 214).

This new interest, which seems to be demanded and driven by donors, is often provided by the mid-level organizations who apply for funding to run media assistance programs and projects (Alcorn et al. 3). Not surprisingly then, the main discussion concerning the methodology and tools for measuring and evaluating media assistance and media development is found in reports by executive media organizations such as BBC World Action, Fondation Hirondelle, Internews, and IREX.

As there is barely a discussion in academia regarding the measurement and evaluation of media assistance or intervention, this chapter is mainly based on two books, Measures of Press Freedom and Media Contributions to Development: Evaluating the $\underline{\text { Evaluators edited by scholars Price, Abbott and Libby, and Evaluating Democracy }}$ Assistance, by Krishna Kumar. Evaluating Democracy Assistance (Kumar 2013) will mainly provide definitions and explanations of terms and concepts such as indicators, monitoring and evaluation in a democracy assistance context. 
Measures of Press Freedom and Media Contributions to Development: Evaluating

the Evaluators (Price, Abbott and Libby) is to my knowledge, the only thorough academic publication concerned with the matter of monitoring and evaluating media contributions to development and democracy. ${ }^{2}$ A review of the main ideas contained in this book will provide background context to the question of how to measure media's role in, and positive impact on development and democracy. The main ideas are, connected to freedom of the press and related indexes.

\subsection{Defining Monitoring and Evaluation}

First, let's establish that although monitoring and evaluation (M\&E) are related, and often mentioned together, they are different from one another. "They are two distinct processes" that "go hand in hand" (Alcorn et al. 6). Krishna Kumar also argues that although they are complementary, "they are conceptually and operationally different" (Kumar 59).

Monitoring has been defined in a number of ways. Andy Mosher defines monitoring simply as, "the tracking of programs and activities as they proceed" (qtd. in

2 This was confirmed by a social scientist at Oklahoma University, and monitoring and evaluation professional of media assistance projects, in an interview April $28,2014$. 
Alcorn et al. 6). ${ }^{3}$ Krishna Kumar, on the other hand, offers a more detailed definition, where monitoring is a "systematic collection of data on an intervention's activities, outputs, and when possible, outcomes" (58). Sometimes, it involves "checking progress against predetermined objectives and targets" (Kumar 58).

The OECD defines the purpose of monitoring to be: "to provide management and main stakeholders of the ongoing development intervention with indicators of the extent of progress and achievement of objectives and in the use of allocated funds" (qtd. in Kumar 58). All three definitions are viable and commonly used, and describe the process of monitoring to different degrees. Data for monitoring are typically gathered and reported with regular intervals throughout a project (Arsenault, Himelfarb and Abbot 16).

While measuring is concerned primarily with data collection during the implementation of a program or project, evaluation is concerned with what happens after. For example, Andy Mosher defines evaluation as the use of data to “assess the program's impact" (qtd. in Alcorn et al. 6). Krishna Kumar argues: "evaluation is more comprehensive than monitoring and goes beyond the tracking of progress" (Kumar 59). In fact, the evaluation process goes deeper and "seeks to identify the underlying factors that affect the implementation process, efficiency, sustainability, and effectiveness of an intervention" (Kumar 59). Krishna Kumar states that the objectives of evaluations "are to promote accountability informed decision making and learning” (59).

${ }^{3}$ Andy Mosher is an international media consultant, writer and editor, most recently with The Washington Post. He has also contributed to reports and chapters concerning media assistance. 
According to the 2011 USAID Evaluation Policy the purpose of evaluation is to provide "the information and analysis that prevents mistakes from being repeated, and that increases the chance that future investments will yield even more benefits than past investments" (qtd. in Alcorn et al. 6). Data for evaluation are "typically collected beforehand (i.e., baseline data), at the midpoint, and at the conclusion of the project" (Arsenault, Himelfarb and Abbott 16).

There are a couple of additional differences between monitoring and evaluation that are worth mentioning: while monitoring mostly uses quantitative data, evaluation uses both quantitative and qualitative data; and, while monitoring focuses on answering the questions 'what' and 'where', evaluation also focuses on 'why' and how' (Kumar $59)$.

\subsection{Indicators: Definitions and Limitations}

There seems to be general agreement among scholars, donors and those working in the field, that it is of great importance to be able to show the positive impact of the media on democracy, but there seems to be no consensus of how to do so (Acorn et al. 3). What is to be measured, how to measure it, and to what end, are the questions at the centre of every tool, method and framework being developed, but with diversity in the answers.

For the purpose of this thesis, I am using a definition that places media assistance within the frame of democracy assistance. Indicators play a vital role in the measuring of both progress and outcome of media assistance. I use Krishna Kumar's definition of indicators, as "a measure used to determine change over time or in space". Indicators can 
be situated in a larger context of measuring, for example they are commonly used in sectors of education, economic growth, health, and family planning (Kumar 310). Furthermore, "they have enabled policy makers and evaluators to monitor progress, measure results, and make comparative analyses" (Kumar 310).

Democracy indicators are often developed by social scientists. In order to get an overview and further clarify the indicators, scholars and practitioners tend to divide them into different levels or schema. Kumar divides them into three categories: micro-level, meso-level and macro-level (Kumar 31). He situates some of the most common indicators used to measure media's relationship with democracy, such as The Press Freedom Index and The Media Sustainability Index, among meso-level indices (31-32).

In this chapter, I will examine the micro, macro and meso-level indices, including the role, importance and problems of indicators, and then focus on the relevant mesolevel indices. This discussion will provide a context to the issue of measuring progress and impact of media assistance at large and specific interventions at a smaller scale.

\subsubsection{Micro-Level Indicators}

Micro-level indicators are used to measure the progress or outcome of an ongoing program or project (Kumar 32). "The purpose of the micro-level indicators is to measure the activities, outputs, and outcomes of democracy interventions" (Kumar 32). Microlevel indicators have two major functions: they can serve to identify problems during the implementation phase, and they may provide data that is useful at either a mid-term evaluation or to after a project is done when the impact is examined (Kumar 38). 
The micro-level indicators can be divided into two sub-categories: "performance and outcomes" (Kumar 32). The performance indicators are useful for monitoring the progress of a project (Kumar 32). They provide data on if targets are met on time, and give a better picture of if the intended end results are likely to be reached (Kumar 32). The "cumulative evidence of several indicators" is what informs the stakeholders if progress is made (Kumar 32).

Indicators of good performance also help managers to be more effective and efficient by specifying targets (Kumar 33). Examples of performance indicators can be: numbers of computers bought with the help of project assistance; numbers of journalists trained (number of men, number of women); number of local unions supported using project assistance; number of independent media outlets set up or supported by project assistance, and more.

However, micro-level performance indicators have their limitations. For example, they only "provide minimal information and do not give details about the quality of the goods and services provided" (Kumar 33). They also have a tendency to oversimplify an often complex reality (Kumar 33). The assumption that "the higher the value of the scores of values of an indicator, the better the performance" is not always justified since it overlooks case-specific conditions that may give a different result if taken into consideration (Kumar 34). Furthermore, performance indicators are not enough to show if a situation would have worsened was it not for an intervention. Other complementary data are needed to estimate the situation (Kumar 34).

Outcome indicators "go beyond measuring performance and are designed to measure the immediate result of interventions" (Kumar 34). In comparison to 
performance indicators "outcome indicators are more difficult to identify" in democracy assistance, than, for example, development projects and programs in the areas of health or agriculture where it is easier to identify outcome indicators (Kumar 34). Outcomes are "the behavioural changes that result from outputs" (Kumar 64). Outputs are the results of activities such as training programs, or technical assistance, and are implemented during an intervention (Kumar 63, 64). Examples of outcome indicators in media assistance can be that a population is better informed about the upcoming elections in a post-conflict period, or that an election commission organizes better and fairer elections.

The difficulty of identifying outcome indicators in democracy assistance, including media assistance, is intrinsically connected to the very nature of the issue, democracy, or as in the case of the media, press freedom. The outcome is not always found in quantitative data. For example, even if a program successfully trains journalists in how to cover elections in a fair and balanced way, it does not ensure that the journalists get access to the political opposition, voters, or polls, prior to or during election day. Or, even though the journalists publish a certain amount of articles after training, there is no guarantee they will be fair and balanced, or that citizens can read them.

As with the performance indicators, outcome indicators have limitations too. For example, they "do not pass the test of reliability and validity" (Kumar 35, 37). ${ }^{4}$ This

4 "Reliability is the extent to which any measuring procedure yields the same result in repeated trials" (Kumar 37). "Validity refers to the degree to which an indicator accurately reflects or assesses the specific concept that the indicator is supposed to measure" (Kumar 37). 
happens, as there is an element of subjective understanding and interpreting of language used in reporting. In short, the outcome can be "interpreted differently by different observers" (Kumar 35). Also, repeated trials may not yield the same result time after time, which makes it difficult to generalize the findings (Kumar 37).

Another limitation has to do with timing and process. Since outcome indicators are meant to measure immediate outcome, they cannot measure limited incremental change, or impact that may occur over a longer period of time, for example, a few years after the assistance has been completed (Kumar 35). Finally, "even when outcome indicators indicate that changes are taking place, it cannot be assumed that the observed changes are the result of a specific project" (Kumar 38). The reason for this limitation is that democracy projects and programs often are complex and consist of many components and partners, and also, because they are a part of a larger context of development programs orchestrated by different donors and stakeholders (Kumar 38).

\subsubsection{Macro-Level Indicators}

Macro-level indices typically consist of larger datasets that are aggregated to give a fuller picture of, for example, the level of democracy, economic development, or environmental sustainability in a country (Kumar 39). They provide "information about the overall context in which programs are designed and implemented" (Kumar 43). Among the macro-level indices measuring the state of democracy, Kumar places the World Bank's Worldwide Governance Indicators, Freedom House's The Freedom in the World Index, The Economist Intelligence Unit's Democracy Index, and Global Barometer Surveys $(39,40)$. 
The US National Research Council summarizes the criticisms of macro-level indices and divides them into five categories: "definitional, sensitivity issues, measurement errors, and data coverage, aggregation, and lack of convergent validity" (Kumar 41). The first issue, definitional, concerns the difference in defining democracy, and that different indices focus on measuring different aspects of democracy; for example, one index may focus on civil and political rights, while another measures electoral democracy (41). Sensitivity issues are concerned with leading indicators being insensitive to "important gradations in the quality of democracy across countries over time" (Kumar 42).

Methodological limitations concerns the way data is gathered quantified and aggregated (Kumar 42). A common method of gathering data is through surveys reflecting people's opinions. Kumar argues that opinion polls can be significantly affected by small events prior to the polls being conducted, and therefore, there is a risk of not always showing actual progress (Kumar 42). Concerning the practice of quantifying experts' evaluations, he points out: "expert judgment are always selective". 5 Aggregating poses the issue of how the components of an index are weighed (Kumar 42). Different indices give different weight, or importance, to different components, since "the rules for assigning weight are not clear and are ambiguous" (Kumar 42). According to the US National Research Council "It is difficult to articulate what an index value of '4' means within the context of any single indicator" (qtd. in Kumar 43).

${ }^{5}$ However, he also recognizes that "their limitations have been widely accepted by researchers and political scientists" (42). 
Despite the critique of macro-level indices, evaluators have "found macro-level data generated by different indices highly useful, but not sufficient" (Kumar 43). Individual interventions and small movements in one country, or between countries, need complementing information from micro-level, or meso-level indices, or qualitative methods that more accurately reflect the rich narrative surrounding democracy interventions (Kumar 43).

\subsubsection{Meso-Level Indicators}

As mentioned above, Kumar places some of the most commonly used press freedom indices among the meso-level indices. Meso-level indices tend to focus on a specific sector of democracy, such as the media sector, and measure the cumulative effects of international assistance on that sector (Kumar 32,43, 44). According to Kumar, the tendency is that this type of index was, and is, developed to answer the demands of policy makers and program managers $(43,44)$. As an example he mentions USAID officials, who wanted "to know the effects of assistance programs on the media sector and the sustainability of independent media in recipient countries" (Kumar 44, 45). In response, the USAID "funded the construction of the Media Sustainability Index" (Kumar 45). A more detailed description of the Media Sustainability Index (MSI) and its objectives will occur further on in this chapter.

The data collected through meso-level indices can be used by evaluators in two ways: "an evaluator can learn about the state of the media sector as well as the changes that have taken place over time"; and they "can be used for identifying evaluation 
questions, developing questionnaires for surveys, and preparing for checklists for structured direct observation in evaluations" (Kumar 47, 48).

Meso-level indices also have their limitations, many of which are similar to the ones of macro-level indices. For example, they are largely based on opinion polls and surveys and thereby they "may be at variance with the empirical reality" and that they often cannot be validated according to academic standards (Kumar 37, 47). However, considering that meso-level indicators were, and are, developed by the combined effort of experts in a certain sector to meet international policy makers demands, Kumar concludes that they are useful for that purpose, in that context (47).

As established, there is a multitude of indicators and indices that can be divided into different categories and levels. When UNESCO investigated the existing methods of measurement of media development to get an overview of the field and to formulate a general set of media development indicators, it found 26 different sets of indicators ${ }^{6}$. The indicators were collected from various organizations involved in a variety of areas, and had been developed with different objectives in mind, were rooted in different institutional cultures, and were therefore sometimes overlapping and even contradictory (Puddephat 70-71). The diversity of indicators relate to national or regional levels, to specific issues or sectors, and aim to either aggregate or disaggregate larger datasets, and

${ }^{6}$ The investigation looked at and took into consideration any type of measurable indicator, both qualitative and quantitative that was in line with the priority areas of the IPDC (Puddephatt 70, "Defining Indicators of Media Development" 3). 
sometimes aiming to show the correlation between media and "another key variable, e.g. governance" (Puddephat 71).

As if 26 sets of indicators were not enough, more indicators are being added as new organizations enter the arena. This chapter is not an attempt to compile taxonomies of tools, methods and frameworks, but rather mention them and discuss the critique around them.

The most commonly used indices will be discussed for the purpose of illustrating specific examples, and for better understanding their limitations as well as their role in a larger and more complex process. I will give a description of the main indices, their indicators, their focus of measurement, and some the critique against them.

\subsection{Indices}

As discussed above, there are a variety of indicators and indices, and many ways defining, and categorizing them. While Krishna Kumar divides indicators into three different levels: micro, meso and macro, there are others who use different divisions.

For example, Shanthi Kalathil, Adjunct Professor at the Monterey Institute of International Studies, divides the efforts to measure and assess media development efforts on democracy into two broad categories: first, one that includes "global and regional indices that measure various markers of press freedom and independent media" such as the Freedom of the Press annual report by the Freedom House, the annual World Press Freedom Index (WPF) by Reporters Sans Frontières (RSF), and the Media Sustainability Index (MSI) by IREX. Second, one that includes reports, surveys, and indicators from donors, NGOs and IGOs, such as the UNESCO Media Development Indicators, USAID’s Handbook of Democracy and Governance Program Indicators $(275,276)$. The first 
category seems to correspond to Kumar's meso-level indicators, while the second category seems to correspond to the macro-level indicators.

Another approach is that of Sandjukta Roy, a development economist affiliated with the World Bank, who divides the indices into three different categories: indices based on expert assessment, composite indices, and quantitative measures of media infrastructure, functionality, and gender representation $(5,6) .{ }^{7}$ In the first category she places indices that "evaluate the media sector at a country level, taking into account the social, economic, and legal environment that supports or undermines the health of the media sector”, such as IREX's Media Sustainability Index (MSI), Freedom House's Freedom of the Press Index, Freedom House's Freedom on Net Index, Reporter's Without Borders' World Press Freedom Index, and the African Media Barometer by Fesmedia Africa (Roy 5). They are essentially “constructed by assigning quantitative numbers to expert qualitative assessments", hence the category. This category basically corresponds to Kumar's meso-level indicators.

The second category, composite indices, "provide a broader analytic perspective on development" and includes the media sector in a larger context of multiple sectors (Roy 6). The Wealth of Nations Index, The World Bank's Worldwide Governance Indicators, and the Global Integrity Index, are examples of indices in this category (Roy 6). They consist of sub-components, and collect and aggregate data from a broad variety

${ }^{7}$ Sanjukta Roy wrote the report "OVverview Report: Measuring Media Development" in 2011, jointly published by Internews, The Media Map project and the World Bank. 
of sources, including data from surveys and expert assessment (Roy 6). This category corresponds to Kumar's macro level indicators.

The third category, quantitative measures of media infrastructure, functionality and gender representation, "consists of indicators that quantify actual units of media infrastructure owned by people, proxies of reach and composition, and statistics on gender representation in the media" (Roy 6). This type of measurement is mostly found in different development-related databanks, such as the World Bank's World Development Indicators, that "consists of indicators like mobile telephones per 100 people" among other similar indicators; or UNESCO's Culture and Communications data that "contain proxies of reach and composition" (Roy 6). This category has close resemblance to Krishna Kumar's micro level indicators.

\subsubsection{The UNESCO Indicators}

The UNESCO indicators are tools that look at the role that the media system plays in a country, as a piece of a larger puzzle. While other indicators may focus on measuring specific aspects of media's role in society with a comparative approach, for example IREX's MSI measures sustainability, and the Freedom House's annual survey, that measures press freedom, the UNESCO indicators involve a more analytical approach looking at each country individually (Puddephatt 86). 
Human rights expert and former Executive Director of Human Rights Article 19, ${ }^{8}$ Andrew Puddephatt, examined UNESCO's interest in developing indicators to measure media development and traced it back to 2006 (Puddephatt 67). The International Programme for the Development of Communication (IPDC) council, an intergovernmental body, decided to conduct mapping and analysis of indicator systems in order to get an overview (Puddephatt 68). The goal "was to produce a global set of indicators that could be drawn upon by the donor community as a whole" (Puddephatt 74). The focus was on "those initiatives that were concerned with measureable indicators, whether qualitative or quantitative" (Puddephatt 70). The process resulted in a final draft of indicators that "was endorsed by the IPDC Council" in 2008 (Puddephatt 68).

The UNESCO Indicators take a toolkit approach in that it offers a set of indicators and methods for the assessor to choose from, depending on the circumstances, the size the level of engagement, and other decisive factors that vary from one national context to another (Puddephatt 74-76). "The toolkit has the advantage that it can be treated as a diagnostic tool without implying any comparison with other countries" (Puddephatt 75).

The toolkit approach is commonly used among UN institutions and donors because of its flexible and adaptable qualities, and can be found in for example some of UNDP's programs as well as the UK Department for International Development (DFID) and The Danish International Development Agency (DANIDA) (Puddephatt 76). The UNESCO indicators are designed as a comprehensive toolkit to meet the needs of these

${ }^{8}$ Article 19 of the Universal Declaration of Human Rights is concerned with the right to freedom of opinion and expression. 
larger actors, and can be used as guidelines already when programs are designed (Puddephatt 86).

The UNESCO indicators have a holistic approach, consider the media environment of a nation, and are organized into five categories of which all five need to be assessed to find out if the media environment supports good governance and democracy on a national level (Puddephatt 77, 78). The categories are: "A system of regulation and control conducive to freedom of expression, pluralism and diversity of the media"; "Plurality and diversity of the media, a level of economic playing field and transparency of ownership"; "Media as a platform for democratic discourse"; Professional capacity building and supportive institutions that underpin freedom of expression, pluralism and diversity"; "Infrastructural capacity sufficient to support independent and pluralistic media" (Puddephatt 77).

These categories, and the tools included, are meant to provide the information that enables "a comprehensive analysis of a current media situation, identify the main gaps to be addressed by donors and indicate the direction reforms should take in order to foster an enabling environment for free, pluralistic media" (Puddephatt 79). According to Puddephatt, "the UNESCO model is the most comprehensive yet", but he does recognize that because it operates on a national level, there is still much it does not cover, for which other models will have to be used in a complementary fashion.

A couple of the findings uncovered while examining the field prior to the creation of the UNESCO indicators, are particularly worth mentioning: first, the IREX Media Sustainability Index and the Freedom House annual Press Survey were the two sets of indicators that were most frequently referred to; second, "most of the methodology 
designed to assess media development face the problem of lack of data" (Puddephatt 72). The lack of data refers to the collection of data, before, during and after a media assistance project is implemented, and the difficulties of consistently compiling this type of data in a manner that makes it useful for scientific research in terms of measuring results and impact. In some countries, certain information needed for the indicators may be inaccessible or simply out of date (Puddephatt 72). To compensate for this lack data, the IREX and the Freedom House use expert panels to provide a score through qualitative assessment - a solution, which, has its own potholes.

The findings concerning lack of data is a concern echoed in Dr. Krishna Kumar's discussion about indicators, and is also mentioned in several other reports (Wanchek and Carter 14, Arsenault, Himelfarb and Abbott 12, Roy 7, Alcorn et al. 11). The issue will be further discussed in the next chapter, in the section about the challenges of conducting monitoring and evaluation in conflict and post-conflict settings.

\subsubsection{The Media Sustainability Index}

As mentioned above, the UNESCO investigation into different tools of measurement showed that IREX's MSI and the Freedom House annual Press Survey were the two sets of indicators that were most frequently referred to (Puddephatt 72). According to Becker and Vlad, the MSI, the Freedom of the Press annual Press Survey, and the Worldwide Press Freedom index from RSF are consistent in their measuring of various aspects of press freedom (Price, Abbott and Morgan).

The NGO International Research and Exchanges Board (IREX), was founded in 1968 by universities in the US with the aim to "administer exchanges with the Soviet 
Union and Eastern Europe" (IREX.org). According to their mission, they "enable local individuals and institutions to build key elements of a vibrant society: quality education, independent media, and strong communities" (IREX.org). In 2001, IREX with support from USAID, introduced the Media sustainability Index (MSI) primarily looking at nations in Europe and Eurasia (Lamay 223, IREX.org). It expanded to include North Africa and the Middle East, and since 2006 IREX also publishes a MSI specifically for Africa.

The index measures the independence and sustainability of media systems over time, using five key criteria or objectives: "free speech and access to public information protected by legal and social norms, quality of professional journalism, plurality and credibility of news, sources, growth of independent media, and institutions supporting independent media" (Jacobson, Pan and Jun 283). "Each criterion has seven to nine indicators rated on a scale of 0 to 4" (Jacobson, Pan and Jun 284).

The process of evaluating each country according to the criteria includes two separate scorings, first a panel of experts ${ }^{9}$ in each country discuss the objectives and indicators and gives a score; second, "IREX staff reviews the results and scores the countries independently"10 (Banda 93). Finally, the average is taken from the final score of each criterion for an overall score (Banda 93). A country can score from 0 to 4: if it

${ }^{9}$ The panel consists of local mass media professionals, NGOs, international donors and media development implementers (Banda 93).

${ }^{10}$ The score from the IREX score carries is equal to an individual score from a panelist (Banda 94). 
gets $0-1$, the media system is unsustainable; $1-2$ is the score reflecting an unsustainable mixed system, 2-3 is a nearly sustainable system, and 3-4 reflects a sustainable system.

\subsubsection{The Freedom of the Press Index}

The Freedom House "has been monitoring the threats to media independence since 1980" (Freedomhouse.org). This is done through the Freedom of the Press Index, "an annual survey of media independence in 197 countries and territories" (Freedomhouse.org). The survey uses a methodology of three categories with 23 questions each that together are worth 100 points in total (Banda 90, Jacobson, Pan and Jun 283). The categories are: legal environment (worth 30 points), political influence (worth 40 points), and economic pressures (worth 30 points) (Jacobson, Pan and Jun 283). The closer to zero a country is rated, the freer and more democratic it is. Hence, if a country or territory gets a score from $0-30$ it is regarded as "free". If rated 31-60, it is rated as "partly free", and if it rates between 61-100 it is "not free" (Jacobson, Pan and Jun 283).

\subsubsection{The World Press Freedom Index}

A third index that is commonly used as a global or regional index to measure free press is the World Press Freedom Index by Reporters Sans Frontier (RSF or Reporters Without Borders). It is an index that focuses specifically on attacks on journalists and the mass media. It "reflects the degree of freedom that journalists, news organizations, and netizens enjoy in each country, and the efforts made by the authorities to respect for this freedom" (RFS.org). The Press Freedom Index has been published since 2002 and at its 
latest publication in 2014 covered 180 countries that are ranked according to the final score that they get (RFS.org).

The index ${ }^{11}$ is based on information from a questionnaire that is sent to 18 freedom of expression NGOs, and "a network of 150 correspondents ... journalists, researchers, jurists and human rights activists" (RFS.org). It provides "counts of journalists killed, attacked, kidnapped, imprisoned, threatened, and media organizations censored and attacked, and will analyze the trends that the numbers represent" (RFS.org). Each country is scored according to six criteria and a variety of indicators. The criteria are: pluralism, media independence, environment and self-censorship, legislative framework, transparency and quality of infrastructure (RFS.org).

\subsubsection{The African Media Barometer}

If the RFS's World Press Freedom Index has a thematic focus, the African Media Barometer (AMB) has a regional focus. The AMB was introduced in 2004, and is a product of collaboration between the Friedrich Ebert Stiftung (FES) and the Media Institute of Southern Africa (MISA) (Banda 94, Fesmedia-africa.org). It "identifies and analyses the shortcomings and best practices in the legal as well as practical media environment of different African countries" (Fesmedia-africa.org). Different African

${ }^{11}$ As of 2013 , RSF changed their methodology, both by modifying the questionnaire that is sent out to their partners, and by letting in-house staff research the quantitative data (RFS.org). Although they use the same criteria as before, the method is different. 
documents such as the African Commission On Human and Peoples' Rights Declaration On Principles of Freedom of Expression from 2002, is used as a benchmark (Fesmediaafrica.org).

FES explain on its website that the AMB as a tool has multiple purposes. It can serve to "lobby for media reform", as well as "an in-depth and comprehensive description system for national media environments on the African continent" (Fesmedia-africa.org). The assessment uses 39 indicators and four criteria. The criteria are: the promotion of freedom of expression and freedom of the media; media landscape diversity, independence and sustainability; transparent broadcasting regulations guaranteeing the transition of state broadcasters into public broadcasters; high level of professional standards of media practice (Banda 94).

The AMB is not a yearly publication; instead a panel meets and discusses indicators and how a country meets the criteria every two to three years (Fesmediaafrica.org). Every country's panel consists of 10-12 local experts including media experts, practitioners and representatives of civil society (Fesmedia-africa.org). Independent consultants and AMB staff are also involved in the writing of the final report (Fesmedia-africa.org). The AMB included 30 African countries by the latest publication in 2011 (Fesmedia-africa.org).

The advantage of this index is that it takes into consideration aspects that are specific for African contexts, such as the transition of broadcasters from state owned to public; that it is anchored in African declarations; and that it is created with the purpose of both comprehensively describing national media environments and as a tool for lobbying. According to Fackson Banda, "it has the advantage of measuring performance 
against self-proclaimed continental standards" (95). However, as the methodology and concept are now spreading to Eastern Europe, the Middle East and Asia, there may be new issues arising in the process or with the final product.

\subsection{Critique of the Indices}

Out of the indices presented above, the Freedom House Freedom of the Press Index is the most rigorous index available in terms of collected data over time concerning the issue of press freedom. As mentioned earlier, it is also the index that is most commonly used by practitioners. The methodology used to rank the countries produces a scale that compares countries to each other and places them in a hierarchical order.

Despite the Freedom House Index's reputation of rigor, scholars have critiqued the method of comparison for its shortcomings, mainly, that comparing vastly different countries can be misleading. For example, Christina Holtz-Bacha, a professor of Communication at the University of Erlangen-Nürnberg in Germany, argues that a comparison on a worldwide scale is futile. She suggests that countries similar to one another in terms of media systems and political systems should be compared (141-142). Nevertheless, she does recognize a value in the method of comparison: "international comparison is needed in order to be able to assess how good press freedom is in an individual country" (141). By using the method of comparison, scholars can find similarities and differences, and trace patterns that "allow for generalizations" (HoltzBacha 141).

Holtz-Bacha also argues "the different philosophies that stand behind the two indexes have a bearing on the ranking (136). With "different philosophies" she seems to 
mean how press freedom is interpreted as a concept. She uses the example of how the United States and various European countries interpret press freedom in different ways, and how this is reflected in factors such as funding and legislation (136-137). According to Holtz-Bacha, the US concept of press freedom is "largely viewed as the absence of or at least minimum of - state regulation of the media" (136). In European democracies on the other hand, the state is commonly seen as having an important role in safeguarding press freedom as well as plurality and diversity of media outlets, and consequently many Western democracies subsidize both public service and print media (136).

Other scholars, like Fackson Banda, refer to the underlying ideology of the different indexes, rather than the different philosophies of press freedom. He labels Freedom House as having a "neoliberal predisposition towards the state as predatory", and IREX as having "indicators and means of verification [that] have an ideological, normative emphasis" favouring privately owned media $(95,98)$. He also argues that the main indexes, such as the Freedom House of the Press Index and IREX's MSI are developed in Western-centric contexts. Indeed, Craig Lamay writes that these two indexes are most commonly used by the U.S State Department and USAID, either together or apart, as evaluation tools of their media programs (223).

McCurdy, Power and Godfrey of the BBC World Trust Fund ${ }^{12}$ argue along the same lines as Holtz-Bacha and Banda, by claiming that measuring press freedom present

${ }^{12}$ The trio wrote a chapter together for Measures of Press Freedom and Media Contributions to Development, Evaluating the Evaluators, as representatives of he BBC 
both ideological and methodological issues (64). They argue that there are risks when the scores "are taken at face value and not seen as the product of normative and ideologically-driven analysis" (63). As a remedy, they call for a change that makes it more transparent how the ideologies manifest themselves in the indicators measuring press freedom of the indices, as well as conducting contextual analysis of the countries of interest to complement the index ranking, rather than just combining the different indices, as is often done by donors (63).

McCurdy, Power and Godfrey find support for their argument in Becker and Vlad's research. It shows a high correlation between the Freedom House Index and the RSF index, and that they are practically indistinguishable ${ }^{13}$ (Becker and Vlad 38). Becker and Vlad also found that although IREX's MSI "is designed to tap something conceptually distinct ... Empirically, however, it too is highly correlated with the Freedom House and Reporters without Borders measures" (38). The high correlation points to a potential problem of methodology.

There is also a range of critiques concerning areas omitted by the indices' present methodology. Representing the approach of the BBC World Service Trust (BBC WST) McCurdy, Power and Godfrey expand their critique of the four indices Freedom Houses The Freedom of the Press Index, IREX's MSI, RSF's Press Freedom Index, and the

World Trust. At present, only Anna Godfrey is engaged with the BBC, now with BBC Media Action. The BBC World Trust is a major actor with its own research unit.

${ }^{13}$ Becker and Vlad's investigation was done based on the MSF Index methodology prior to the change in the 2014 index. 
AMB beyond ideology. Their critique is mainly concerned with the lack of an audiencebased approach, and "the use of the term media as an aggregate variable in multiple items," and how this limits the type of impact measured, and the resulting information made available (McCurdy, Power and Godfrey 49).

The issue of audiences is an interesting one, since attracting audiences is a major goal of media everywhere. An audience is one of media's raison d'être. So far, however, the existing indices focus more on journalism and journalists, as well as type and range of coverage, rather than on what the BBC calls "use" of information, referring to how audiences use media (McCurdy, Power and Godfrey 50, 51). The IREX Media Sustainability Index does raise the issue of access to media and information, but the question targets censorship of content rather than the why, what and how citizens access media (McCurdy, Power and Godfrey 50). Audiences' confidence in the media system, or how trust-worthy it is, is also an omitted issue (McCurdy, Power and Godfrey 50).

An audience-based perspective can supply information about the media (both as type of platform and in terms of content) available to different audiences, and how they use the information acquired from this platform (McCurdy, Power and Godfrey 51). It can also be used to find out if media serve the audiences the information they need (McCurdy, Power and Godfrey 51).

The type of media available to the audience can provide information on what type of programming audiences tends to follow: news, current affairs, soap operas, reality shows, talk shows etc., as well as what type of programming they find trustworthy. While press freedom indicators tend to focus on news and current affairs, there are studies showing that other types of programming, such as talk radio or reality shows, can have an 
impact on audiences, both negative and positive (McCurdy, Power and Godfrey 57). For example, talk radio hosts played a pivotal role to both incite violence and later calm it down during the 2007 Kenya elections (McCurdy, Power and Godfrey 57). Thus, expanding indicators to include programming beyond news and current affairs can offer a fuller picture of the media landscape and its impact on society.

The issue of whether media provides useful information, is particularly relevant if one assumes that media development has a public service mission, "to reach and serve" the public (McCurdy, Power and Godfrey 50). There have been calls to improve the media as a platform for the expression of citizen voice, and include it as a main objective of media interventions (McCurdy, Power and Godfrey 51, Jacobson Pan and Jung 285). A part of the process would mean to re-conceptualize a potentially passive audience into active citizens, according to Jurgen Habermas's theory of how citizens assess democracy based on the level and availability of participation in the public sphere (McCurdy, Power and Godfrey 50, Jacobson Pan and Jung 287).

Presently, there are few assessment tools that include citizen voice (Jacobson Pan and Jung 287). The Freedom House index and the MSI have questions that consider citizen voice, but the answers tend to be acquired from media professionals and experts rather than the citizens themselves (Jacobson Pan and Jung 286). The UNESCO Media Development Indicators is currently the only index including audience-based indicators (McCurdy, Power and Godfrey 52).

Another aspect of an audience-based approach is, that it has the potential to recognize audiences as producers of content (McCurdy, Power and Godfrey 52). This is especially relevant on web-based platforms, including mobile telephony, which create 
new avenues for citizens to engage in public discussion (McCurdy, Power and Godfrey 52). Web-based participation is worth considering as an indicator on its own, but is often either omitted or lumped together with print, radio, and television, as "mass media" (McCurdy, Power and Godfrey 52). Differentiating between platforms and including new media indicators, is especially relevant concerning the rise of smartphones as a new platform to both access and produce various content (McCurdy, Power and Godfrey 54).

New media (web-based media platforms including blogs, YouTube, Twitter etc.), and Information Communication Technologies (ICTs) (smartphones, tablets and such), have come to play a crucial role in "facilitating freedom of expression and access to information" in developing democracies and closed of societies (McCurdy, Power and Godfrey 54). The Jasmine Revolution that swept over North Africa in 2010 serves as a recent example. Given the importance of new media, McCurdy, Power and Godfrey's argument for disaggregating media in order to differentiate between platforms, and make sure that "new media are included in any media environment analysis" has a sense of urgency about it (52). This methodological change may make it harder to compare countries with each other, but in turn, it will add valid information when measuring the effect and impact of media on democracy, as well as of media interventions.

It is also valuable to disaggregate media to acquire information concerning ownership and control of media outlets (McCurdy, Power and Godfrey 52). When different media outlets and platforms are lumped together as "mass media" or "media", the nuances within the media system are lost, as is the possibility to measure changes or variation over time (McCurdy, Power and Godfrey 53). Furthermore, the opportunity is lost to "contextualize the response" of an index question, for example in order to bring to 
attention the political ideology and mission of the owner (McCurdy, Power and Godfrey $53)$.

\subsection{Reflections}

This chapter shows that there are a number of models and methods, indicators and indices, as well as a variety in terminology and understanding of this terminology. The issue of terminology and some of the resulting complications will be further visited in the next chapter. The discussion concerning indicators, how they are defined and organized, and what level they should be placed in - micro, meso, or macro, is worthy of a study in itself. I chose to focus on Kumar's discussion concerning indicators, since he gives a comprehensive overview and explanation including relevant critique. Roy’s and Kalathil's perspectives and represent two, out of many, alternative ways to organize, categorize and understand the indicators and indices presently used.

I have presented the most commonly used indices, and discussed some of the critique of their effectiveness. As noted in this chapter, measuring the media's relationship to democracy is not a simple thing. Although most scholars and practitioners recognize that the indices presently used are both necessary and useful, as this chapter has demonstrated, there is also an ongoing discussion concerning their shortcomings. There are interesting and relevant aspects of the critique of the indices, including underlying ideology, the issue of neglecting new media and mobile telephony, and the exclusion of an audience-approach. The issue of ideology is connected to the idea of media's role in society, and relationship to democracy. The question comes to mind if Western donor countries only are interested in measuring the export of Western 
normative systems through their media assistance programs. Doubtlessly, the normative system of a liberal democracy is intrinsically connected to and a part of media assistance. Hence, measuring the level of press freedom is one way of measuring success. While ideology may be a limiting factor, it is not the only way to measure success, or the sole purpose of the indices.

Interestingly, it raises a discussion similar to the one concerning media's objectivity, namely, asking how objective and neutral the indicators of specific indices are. The suggestion from the BBC World Trust Fund, to be more transparent and show how the indices are influenced by norms and ideology, is an interesting one. So is its idea of doing a contextual analysis of a country to complement index findings, instead of just combining different indices. This is especially relevant considering Becker and Vlad's findings of the high correlation between The Freedom Press Index, IREX and the RSF index. By providing "ideological transparency" and a context, the complexity of media's relationship to democracy and press freedom in a country may be illuminated and thus better understood.

The issue of neglecting new media and ICTS seems almost ludicrous in postJasmine Revolution times. Either excluding new media such as blogs, forums, and social media, or lumping it together with traditional mass media such as radio and television, seems hopelessly old fashioned. New media and ICTs have changed the media landscape and how audiences interact with media platforms and content, and deserve to have their own indicators. The result of an index measuring press freedom while omitting new media and ICT is probably worth questioning in most cases. A solution could be to 
develop a new set of indicators specifically tailored to measure the activity related to new media and ICTs.

The related issue of audiences could be a thesis in itself, and is worthy of a deeper analysis. As mentioned, the audience is the media's reason for being, at least for mass media targeting the broader segment of a population. How audiences use the media, and if they trust the information from the media, is much coveted knowledge by news organizations and funders of media globally, not only in a development context. Yet, surprisingly, as established in the research by the BBC World Trust, there are few indicators that focus on the audience. This is an issue when measuring press freedom, and also when measuring and evaluating media assistance. Reframing the audience, from passive audience into participating citizens, seems like a promising alternative, and relevant in relation to the increase of new media and ICTs.

The tools available leave more to wish for, hence, they are regularly revisited, revised and updated and there is an ongoing debate regarding how to best measure the impact of media assistance. It is telling that one of the indices, the RSF index, modified their questionnaire in 2013 as part of the ongoing update of methodology. It is also of interest that the UNESCO indicators, the most recently developed set of global indicators, use a toolkit approach, where different indicators can be used in different combinations depending on the country's context. This method is moving away from, or seen as complementary to, the comparative approach, and is already used by major donors such as DFID and DANIDA.

Although, the UNESCO indicators are a viable alternative, indices such as the MSI and the Press Freedom Index, are still often used as "proxy measurements for the 
success or failure of a specific program", or a healthy media sector, even though they were not originally designed or intended for this purpose (Arsenault, Himelfarb and Abbott 21, Roy 7).

Arsenault, Himelfarb and Abbott argue for the necessity to develop specific tools, or "standardized project-level indicators", to assess "media-related outcomes in the context of a range of conflict-related conditions" (21). Their suggestions and arguments will be examined in the next chapter, where I will also take a closer look at the conflict and post-conflict contexts and the particular problems they pose to assessment. Some of the discussion in chapter one will be revisited, concerning the challenges media faces in conflict and post-conflict societies, and build upon with discussion about challenges facing those assessing the impact of media assistance. 


\section{Challenges of Monitoring and Evaluation of Media Assistance in Conflict and Post Conflict Settings}

\subsection{Introduction}

In chapter one, I discussed the relationship between media and democracy, and the role of press freedom in the democratization process. The chapter also examines the origins and history of media assistance and information intervention and provides working definitions for both. I make the case that media sectors in post-conflict countries need assistance to move on from conflict dynamics, return to their role of a fifth estate, and build healthy political economies.

Chapter two, explored some of the specifics of how the measurement methodologies work, including a discussion of indicators, and related terminology for assessing media assistance and its impact in general. Furthermore, I identified the uses and limitations of the most commonly used indices.

In this chapter, I will narrow the subject further by focusing on the particular issues and challenges surrounding the assessment of media assistance and information interventions that arise specifically in conflict and post-conflict settings. As discussed in chapter one, societies experiencing conflict or recently emerging from conflict, present unique problems for the media assistance monitoring and evaluation community.

The institutions and individuals that constitute the community of donors, NGO and IGO professionals, scholars, and monitoring and evaluation professionals, are actively working to improve the protocol of assessment. In December of 2010, some of 
the key players gathered at a conference in Caux, Switzerland, to exchange experiences and formulate a roadmap for further improvement, the Caux Guiding Principles. I hope that the account and analysis of the issues faced by this community, will lead to a better understanding of what led to the Caux Conference and the creation of the principles.

\subsection{Specific Kinds of Media Assistance}

It might seem almost self-evident to assert that media in countries dealing with conflict or in countries emerging from conflict have particular assistance needs different from those of media operating in countries not facing such circumstances. However, understanding the nature of those needs and the challenges they present to the assistance community is another matter. That is where proper and thorough assessment (monitoring and evaluation) of media assistance can play an important role, by offering insights into the specific needs and challenges facing media assistance in conflict and post-conflict situations. The learning gained from this assessment of media assistance can help donors and practitioners better tailor their programs and projects to the particular needs of their recipients.

The fact that different domestic situations and challenges facing media organizations require different forms of assistance is recognized in the report "One Size Does Not Fit All”, in which, Krishna Kumar divides nations that receive external development assistance of different kinds into four categories: authoritarian, democratizing, war-torn and post-conflict. The categories correspond to the Department of State's Office of the Director of the U.S. Foreign Assistance ("One Size Does Not Fit All" 1). Kumar argues that each category of nations has its own set of problems, and 
hence, needs and requirements of development interventions, including media interventions (3). For the purpose of this thesis, I will mention the problems, needs and requirements related to the categories of war-torn and post-conflict societies.

War-torn societies are "countries with ongoing civil wars, which undermine existing political and economic structures and contribute to humanitarian disasters" (“One Size Does Not Fit All” 2). In this setting, information interventions have the main goal of providing "increased access to balanced news and information and to pave the way for a peaceful resolution of conflict" (“One Size Does Not Fit All” 2). The three main objectives of media intervention are: to provide "access to accurate news", "disseminate information about humanitarian assistance programs", and "to promote understanding and facilitate negotiations among the warring groups" ("One Size Does Not Fit All" 4). This type of intervention is often done by intergovernmental organizations such as various UN agencies. For example, in 2002, the UN mission in the Democratic Republic of Congo set up the radio network Radio Okapi together with the Suisse media NGO Fondation Hirondelle for this purpose.

Post-conflict societies provide a context where civil war is over, "either through peace accords or a total victory of one party over the other, leading to the establishment of a legitimate government" ("One Size Does Not Fit All" 2). The "post-conflict phase" of a society is deemed to last for approximately five years after the resolution of a conflict (“One Size Does Not Fit All” 2).

The goals of media assistance in post-conflict societies are multi-facetted. There are high expectations and much to be accomplished: "international media assistance is designed to support the growth of independent media that can promote democracy and 
development", “ . . . it is also expected to heal the wounds of war by promoting mutual understanding among parties engaged in war" (“One Size Does Not Fit All” 2). The objectives are, hence, "to rehabilitate and restructure the shattered media sector, laying the foundation for an independent, pluralistic media ... in a manner that strengthens the peace process" (“One Size Does Not Fit All” 4).

As part of reviving and rebuilding the media sector, the following can be helpful: provide short-term and medium-term training in print and broadcast journalism to both new and existing journalists; financial support to purchase equipment in case of it having been stolen or destroyed during conflict; training in business management and technical assistance for media outlets to become independent; and training journalists of different local media organizations in how to cover elections in a fair and balanced way, including information on how to vote and why it is important (“One Size Does Not Fit All” 28-30).

\subsection{General Challenges in Conflict and Post-Conflict Settings}

Conflicts are as diverse as their underlying causes, and tend to proceed through a series of different stages. These stages vary in number and are labeled differently depending on the institution or scholar defining them. The fact that almost every donor uses a different definition of the conflict cycle and its various stages may cause problems, or confusion at the very least, both in terms of designing and implementing interventions.

The organizations that design programs and projects have to learn the specific terminology and models used by the different donors to have a chance to receive funding, a process that may be costly, both in terms of time and money. The variety of stages and definitions used also make it difficult for researchers to develop "research methods that 
allow for comparison between and across conflict zones". This, in turn, poses an issue for the community of practitioners and scholars who try and measure the impact of the interventions (Arsenault, Himelfarb and Abbott 12).

For the purposes of this thesis, I will use the general collection of stages defined by Arsenault, Himelfarb and Abbott, as I have found their characterization and categorization of the various stages to be comprehensive, insightful, and helpful in understanding the conflict process. They mention nine different stages: "no conflict, latent conflict, emergence, escalation, stalemate, de-escalation, settlement/resolution, post-conflict peace building, and reconciliation" (Arsenault, Himelfarb and Abbott 12).

The fact that almost every donor uses a different definition of the conflict cycle and its various stages may cause problems, or confusion at the very least, both in terms of designing and implementing projects. The organizations that design programs and projects have to learn the specific terminology and models used by the different donors in order to have a chance to receive funding, a process that may be costly, both in terms of time and money.

The variety of stages and definitions also makes it difficult for researchers to develop "research methods that allow for comparison between and across conflict zones". This, in turn, poses an issue for the community of practitioners and scholars who try and measure the impact of the interventions (Arsenault, Himelfarb and Abbott 12).

Since media assistance may consist of a long-term program and include multiple projects, such as, training local journalists, or establishing a new media outlet, it is very likely that it lasts through several stages of a conflict. As a result, the objectives of a media program may change from, for example, establishing a media outlet that provides 
information about refugee camps and food transports during a conflict, to training reporters in election reporting, and administrative staff on how to become financially independent during the post-conflict phase (Arsenault, Himelfarb and Abbott 12,13).

As established, the contexts of war-torn or post-war societies pose complexity both in terms of media's role, and in terms of measuring and evaluating the potential impact of media interventions. Arsenault, Himelfarb and Abbott have identified a set of general challenges faced by those who have the task either to implement programs or to conduct monitoring and evaluating in conflict environments. The challenges include: diversity of conflict environments, shifting objectives according to changes in conflict, lack of control over research environment, difficulties in measuring the causal impact of media interventions, unreliable data about media usage, media's multiple roles in conflict and rapid shifts in international public and donor attention (Arsenault, Himelfarb and Abbott 9).

The underlying cause of a majority of the challenges mentioned above is the lack of security and safety, which are two of the most serious issues in conflict societies ("One Size Does Not Fit All” 27). The lack of security can be a threat both to program implementation and research for monitoring and evaluation purposes (Arsenault, Himelfarb and Abbott 9). For example, a bad security situation can lead to lack of control over the research environment, or pose difficulties when trying to measure the causal impact of media interventions, which may result in unreliable data about media usage. It may also lead to shifting objectives when the conflict goes into a new, more violent phase. Forty percent of the UK Department of International Development (DFID) 
programs being monitored and evaluated in fragile states in 2009, were disrupted because of security reasons (Arsenault, Himelfarb and Abbott 10).

This reality in the field also affects the methodological issues surrounding the collection of data. As mentioned in the previous chapter, when it comes to democracy assistance, there is no secure way of establishing that a specific project causes the intended change for which it was designed. This also holds true for media assistance in conflict settings, where a number of factors make it more difficult to collect data needed to assess impact. Unexpected shifts in conditions on the ground may cause loss of control over the research environment, and "a carefully detailed evaluation plan constructed at the beginning of a project may well prove untenable" (Arsenault, Himelfarb and Abbott $10)$.

A good example of such shifting conditions, are the security situations facing journalists. When journalists are detained by authorities or are forced to flee a country, it makes it difficult for researchers to interview them about the training they participated in through a media assistance program. Shifting and unexpected conditions can also arise when media outlets are closed, taken over by government, or occupied by militia, and when audiences are displaced and hard to find or interview (Arsenault, Himelfarb and Abbott 10). This makes it difficult for researchers to collect the baseline and intermediary data necessary for measuring improvement, and thus evaluating the impact of a project or program (Arsenault, Himelfarb and Abbott 12).

Another factor that affects the quality and level of assessment performed is the cost of conducting monitoring and evaluation. Travelling in unsafe conflict and postconflict areas is expensive and may put researchers' lives at risk (Arsenault, Himelfarb 
and Abbott 10). To keep the monitoring and evaluation professionals safe, extra logistics may be needed, such as safe housing, and secure vehicles, security guards, and translators. Funding is not always secured or allocated to cover the extra costs, or even prioritized when needed. When secured, the time and money are often limited, and the evaluations often focus on measuring the expected results, thus risking missing unanticipated but still significant outcomes (Arsenault, Himelfarb and Abbott 15).

Conditions in conflict zones are not the only things affecting the quality of monitoring and evaluation -- conditions in the donor countries are also a factor. For example, political trends tend to have an effect on what and where the international community of donors invest efforts and funding (Arsenault, Himelfarb and Abbott 9). A donor country's political and financial agenda, elections, military involvement etc., may cause rapid shifts in international donor attention, as well as the attention of the international media and public (Arsenault, Himelfarb and Abbott 10). The sudden attention on a conflict or post-conflict area may cause "the fishbowl effect", where donors are feeling pressured to show that their interventions are having a positive effect, which may lead to hastily conducted evaluations (Arsenault, Himelfarb and Abbott 10). On the other hand, once out of the public eye, a program may lose its funding, including funding for monitoring and evaluation (Arsenault, Himelfarb and Abbott 10).

\subsection{Monitoring and Evaluation-Related Problems and Suggested Improvements}

\subsubsection{The Donor-Practitioner relationship}

As mentioned in the last chapter, and as further discussed in this chapter, donors play an important role in the demands on, and development of, indicators. Donors, 
practitioners and academics confirm that emphasis on monitoring and evaluation has increased during the past two decades (Alcorn et al. 3). There are multiple reasons for donors to focus on monitoring and evaluation: governments are demanding greater accountability; monitoring and evaluation offer opportunities to learn from the past in order to improve practices for the future; and the results of monitoring and evaluation help legitimize programs by showing successful impacts (Alcorn et al. 3). ${ }^{14}$

However, the process of developing and applying monitoring and evaluation methods and practices is by no means friction-free. Researchers, media development practitioners and donors all bare witness to the difficulties encountered along the road. The relationship between funders and organizations implementing media assistance is at times a complex one, and can affect assessment processes. As mentioned above, funding is one aspect, while expectations are another. Both can encroach on the quality of monitoring and evaluation. To improve the situation and the relationship between the different parties involved, donors, media NGO representatives, academic researchers and evaluators identified three areas to work on: (i) encouraging realistic expectations; (ii) promoting clarity about evaluation requirements; and, (iii) improving conflict specific research methods" (Arsenault, Himelfarb and Abbott 13).

${ }^{14}$ Interestingly, however, there is no proof of evaluation reports having an impact on policy (Alcorn et al. 3). 


\subsubsection{Encouraging Realistic Expectations}

The encouragement of realistic expectations needs to take into account three factors: evaluations are often testing for results in "the immediate aftermath of an intervention"; there is pressure on researchers conducting the evaluations to report a positive outcome; and evaluators tend to test for anticipated results (Arsenault, Himelfarb and Abbott 15).

Addressing the first issue calls for a solution that would include follow-up assessments made long after a project is over, with the purpose of testing for actual longterm impacts (Arsenault, Himelfarb and Abbott 15). For the second issue, the pressure to report positive outcomes, researchers conducting the assessment can use multiple methods "in order to cross-verify findings and test for unexpected outcomes" (Arsenault, Himelfarb and Abbott 15). The last issue, the tendency to test for anticipated results, can be mitigated by incorporating "emergent practices such as participatory evaluations," that offer a program's stakeholders the opportunity to "actively participate in all stages of the research, from planning and design to forming conclusions and future recommendations" (Arsenault, Himelfarb and Abbott 15).

For the second issue, the pressure to report positive outcomes, researchers conducting the assessment can use multiple methods "in order to cross-verify findings and test for unexpected outcomes" (Arsenault, Himelfarb and Abbott 15). The last issue, the tendency to test for anticipated results, can be mitigated by incorporating: "emergent practices such as participatory evaluations," that offer a program's stakeholders the opportunity to "actively participate in all stages of the research, from planning and design 
to forming conclusions and future recommendations" (Arsenault, Himelfarb and Abbott $15)$.

\subsubsection{Promoting Clarity}

The second area to improve upon involves increasing the clarity of evaluation requirements. This could be done in three ways: "(1) using clear and consistent terminology; (2) standardizing reporting requirements within and across funding agencies; and, (3) cogently articulating project goals and outcomes and the theoretical assumptions that link them to project activities" (Arsenault, Himelfarb and Abbott 15).

In striving for improved clarity in evaluation requirements, the issue of the terminology used by practitioners, academic researchers and donors is an important factor to consider and address. For example, there is a discrepancy between parties about the use and meaning of such terms assessment, monitoring, evaluation, outputs, outcomes, and impacts. . While the community of social scientists and monitoring and evaluation professionals refers to these terms as steps within a framework, used to illustrate the cause and effect of a program, donor program officers and NGO practitioners, on the other hand, being less familiar with the terminology, may apply the words interchangeably (Arsenault, Himelfarb and Abbott 15,16).

A consequence of this semantic confusion is the disruption of effective monitoring and evaluation, which prevents "the sharing of best practices and lessons learned" (Arsenault, Himelfarb and Abbott 15). To address this issue, "all stakeholders need to work proactively on using clear and consistent terminology", and, donors should cooperate to "develop and agree on common vocabulary" (Arsenault, Himelfarb and 
Abbott 16). Furthermore, Arsenault, Himelfarb and Abbott suggest that the OECD Glossary of Key Terms in Evaluation and Results Based Management should serve as the go-to dictionary of definitions, since it provides a comprehensive vocabulary (Arsenault, Himelfarb and Abbott 16).

Another problem is the lack of consistency regarding reporting requirements and the absence of a standardized system. In other words, different donors tend to use different models of reporting (Arsenault, Himelfarb and Abbott 16). Those who work on designing and implementing programs and projects are especially frustrated with the lack of consistency in the use of logical frameworks by different donors (Arsenault, Himelfarb and Abbott 16).

A logical framework matrix is a results chain, or map, of a program or project, and its intended achievements, and is developed and given to the donor prior to the implementation of a program or project (Arsenault, Himelfarb and Abbott 17). It was developed in the 1960 s by USAID, but today there is a variety of matrixes or models, since most donors have adapted or changed terminology, and sometimes the order of content (Arsenault, Himelfarb and Abbott 18). ${ }^{15}$

${ }^{15}$ Examples of major donor logical framework matrixes can be found as an appendix to this paper. 


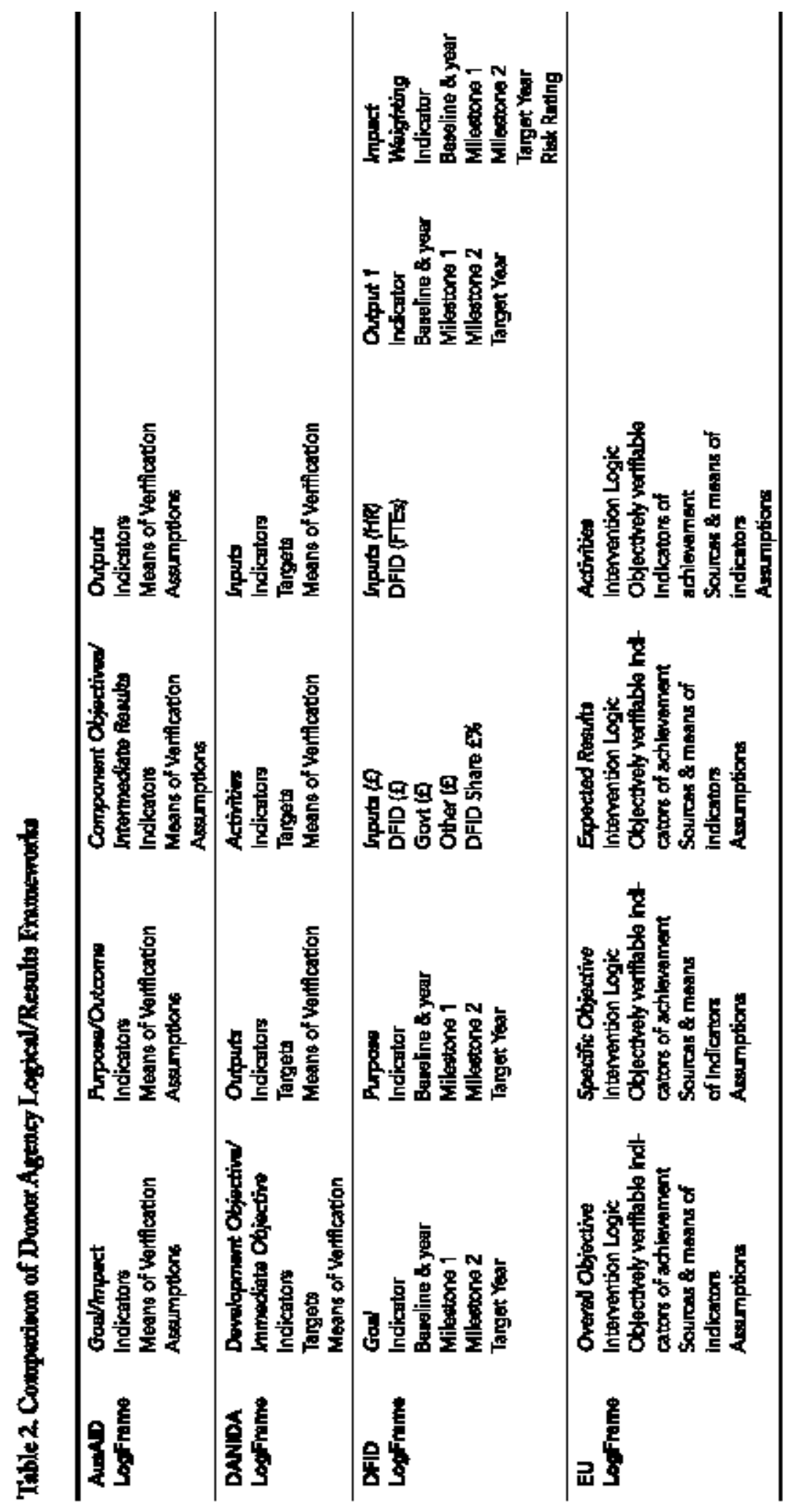

Table 2. Comparing donor agency logical framework matrixes (Arsenault, Himelfarb and Abbott 18) 
Lack of consistency in such framework matrixes can become particularly problematic when there are multiple donors co-funding a program or project, and they all demand different logical framework matrixes (Arsenault, Himelfarb and Abbott 17). It would be helpful to media NGOs designing programs if reporting requirements within and across funding agencies were standardized. Ultimately, a standardized system would make the monitoring and evaluation process more efficient (Arsenault, Himelfarb and Abbott 17).

Another problem relating to logical frameworks is when the donors and implementers do not have a clear a theory of change. An absence of a theory of change may lead to an unclear structure and purpose of the logical framework. "A theory of change is the set of beliefs or assumptions about how change happens" and is a method used by social scientists when conducting research (Arsenault, Himelfarb and Abbott 20). Social scientists thus formulate a theory of change that they systematically test through research. Therefore, "it is critical that implementers and donors agree on and clearly define the different steps to project planning, execution, and evaluation outlined in the project's logical framework" (Arsenault, Himelfarb and Abbott 20).

More often than not, theories of change are missing from the logical framework matrixes, which, "impedes the learning from the research process, because there is no systematic test of which theories work and which do not" (Arsenault, Himelfarb and Abbott 20). The use of clearly articulated theories of change "are an elemental best 
practice because they help donors, implementers, and methodologists get on the same page and agree on the right research questions" (Arsenault, Himelfarb and Abbott 20). ${ }^{16}$

The issue of theory of change is an interesting one, since it is at the heart of the discussion about media development indicators. A theory of change helps to formulate the right questions, which, in turn, improves the measurement of impacts, and informs the understanding of how media may contribute to democracy, as well as to wider development goals (Puddephatt 67).

\subsubsection{Conflict-Specific Approaches to Research Methods}

Not only the relationship between donors and implementing organizations need to be worked on for the general improvement of common practice, monitoring and evaluation need to be adapted to conflict and post-conflict settings. Arsenault, Himmelfarb and Abbott, suggest that this should be done in three steps: (1) "adapting research methods to conflict environments", and (2) "engaging with, and building capacity of local researchers", and (3) "expanding the number of media-specific conflict indicators," (21).

The first suggestion for improvement involves the research methods of monitoring and evaluation in conflict and post-conflict environments. As discussed

16 They list a number of theories of change related to media interventions in conflict environments: individual change theory, healthy relationships and connections theory, political elite theory, grassroots change theory, and public attitudes theory (Arsenault, Himelfarb, and Abbott 20). 
earlier, it can be challenging to apply traditional research methods in conflict and postconflict settings. Hence, adapting research methods, and allowing for flexibility in plans and funding, may allow for better research conditions and results. For example, it may be easier to collect qualitative data rather than quantitative data, or it may be necessary to use participatory methodology such as focus groups. In addition, flexibility in planning may help secure access to interview subjects. Further, allocating funding beforehand for unexpected situations on the ground may also serve to improve the research conditions (Arsenault, Himelfarb and Abbott 22-23).

The second suggestion for improvement concerns those who conduct the monitoring and evaluation. Donors and NGOs commonly pay external professionals to do this work. These professionals, (referred to by some as researchers, and by others as methodologists) are often based in the donor agency countries. When compared to the option of engaging local researchers, using professionals from donor countries can be disadvantageous, due to the extra costs of travel involved, and given their potential lack of familiarity with the issues on the ground. (Arsenault, Himelfarb and Abbott 22).

Local researchers tend to have more knowledge concerning, for example, local security, politics, and socio-cultural issues, as well as the ability to speak local languages, giving them the ability to communicate with local institutions and individuals (Arsenault, Himelfarb and Abbott 22). The knowledge possessed by local researchers, helps during the whole project cycle, from the planning and research stages, during the monitoring stage while a project is implemented, and in the final stage when a project is being evaluated (Arsenault, Himelfarb and Abbott 22). 
The third suggestion for improvement is aimed at addressing inadequacies of the conflict indicators that are used (Arsenault, Himelfarb and Abbott 21). One of the main concerns with existing indices is that they were not developed to measure the outcome or impact of a specific project in a conflict or post-conflict setting. Furthermore, a 2010 USAID report on indicator gaps in media development concludes that although many organizations have developed tracking tools, they do not necessarily qualify as indicators (Wanchek and Carter 1). Despite their own critique of existing indices, the USAID continues to use them. However, they are also observing other organizations engaged in the process of developing new sector indicators, and participating in discussions concerning the development of indicators (Wanchek and Carter 2, 17).

With the scarcity of quality, context-specific indicators in mind, Arsenault, Himelfarb and Abbott argue that it is necessary to develop standardized project-level indicators designed to "assess media-related outcomes", and that are constructed to measure both quality and quantity of specific interventions, and adapted to a range of conflict and post-conflict settings (21). In short, they suggest a toolkit approach with context appropriate indicators. The objective of these new indicators should be to show the donors and stakeholders whether the media programs and projects are promoting peace building or not (Arsenault, Himelfarb and Abbott 21).

\subsubsection{The Caux Guiding Principles}

Arsenault, Himelfarb and Abbot's report summarizes the main points and insights of a conference held in Caux, Switzerland, December 13-17, 2010. The conference was part of a larger, ongoing, decade-long discussion, involving donors, media NGOs, IGOs, 
academic researchers, private sector researchers, and monitoring and evaluation professionals.

The five-day conference focused on "how to better evaluate media's impact in ameliorating conflict ... as a critical step forward for using the media in conflict prevention and peacebuilding" (Arsenault, Himelfarb and Abbott cover page). The goal was to share experiences, insights and methods, and usher a process of developing "a shared set of approaches and best practices for evaluating the role that media and information programs can and do play in conflict and post-conflict countries" and start a process of forming a community of practice that would be active beyond the time limit of the conference (Abbott qtd. in Alcorn et al. 9).

The most prominent feature of the Caux Conference was the Caux Guiding Principles. They are a set of eight principles of how to improve the process of assessment, including the suggestions mentioned in above sections of this chapter. The principles are open-ended, and were "designed to be evolving rather than confining and exhaustive" (Abbott qtd. in Alcorn et al. 9). For the purpose of this study, I will include the Caux Guiding Principles and their explanations in their entirety, as documented by Arsenault, Himelfarb and Abbott.

Principle 1. Expand financial support for evaluation of media interventions in conflict countries

Improving the efficacy and impact of media-related programs through evaluation requires a serious financial commitment. Recognizing the critical role of evaluation, Caux signatories agree whenever possible, to the following: 
- Dedicate between 3 percent and 10 percent of media program budgets to monitoring and evaluation programmatic activities, goals and objectives.

- In case of large-scale projects, allocate separate funding for impact evaluation.

Principle 2. Encourage flexible program and research designs that are sensitive to changing conflict conditions

Fragile states often require flexible and creative approaches to evaluation research. The outbreak of physical violence, unexpected renegotiations of political power, rapid movements of population, and unforeseen humanitarian emergencies are just a few factors that should influence project activities and their evaluation. Therefore, a project should not only be measured according to whether it achieved the expected outcomes outlined at the outset. Project outcomes and objectives should be reassessed and reevaluated in the face of rapidly changing conditions on the ground. At the same time, for those working conflict environments, choices in program design can have life-or-death consequences. Consequently, those involved in evaluating these programs, assume an added responsibility to collect data in as consistent, rigorous, and ethical manner as possible. Before initiating any project, participating entities agree, wherever possible, to do the following:

- Develop an evaluation plan and timeline consistent with the political, security and development environment.

- Conduct a thorough assessment of the media landscape in its political context, incorporating the views of local stakeholders. 
- Investigate the dynamics of the local media marketplace e.g., inflated local salaries or airtime charges, and how the proposed media project might alter those dynamics.

When conducting evaluations, participating entities agree, wherever possible, to do the following:

- Use conflict-sensitive approaches when selecting and training local researchers and enumerators. Conflict-specific approaches vary according to the specific nature of the conflict. They may include, for example, paying particular attention to the demographic makeup of the research team, if it is working in an area where ethnic or racial tensions are high.

- Make every reasonable effort to make sure the safety and security of researchers and those from whom research material is collected. In particular, research should be planned and conducted with extreme care in areas where investigators have little basic data or advance knowledge.

- Conduct rolling risk assessments to minimize unintended consequences (e.g., physical risks to project staff, risk of inflaming ethnic or sectarian tensions).

- Be flexible in amending project outcomes in light of monitoring reports or in response to changing on-the-ground conditions that may have important implications for researchers and implementers.

Principle 3. Carefully select conflict-specific media indicators

Research methods developed in stable environments are often untenable in conflict situations. Researchers should actively work to develop methodologies tailored to conflict scenarios. Methodologists and the academic community can also support better 
evaluation by developing and using project-level measurement criteria that probe the relationship between media projects and peace building. Accordingly, supporters of the Caux Principles agree, wherever possible, to do the following:

- Encourage and facilitate collaboration between methodologists and academics to develop project-level indicators that link media projects to peace building.

- Design research frameworks that address a range of evaluation criteria (e.g., project relevance, effectiveness, sustainability, consistency with values) specifically tailored to the social, political, and economic environment in question.

Principle 4. Engage and collaborate with local researchers familiar with conflict conditions

Conducting research in conflict environments requires that evaluators foresee resistance to the demographics of research teams, respond appropriately to rapidly shifting safety conditions, and navigate the often-complex steps to securing the formal and informal permissions necessary to collect data. Local researchers are often in the best position to advise on these issues. Therefore, the international community needs to broaden its commitment to training and using local researchers. In recognition of this fact, supporters of the Caux Principles agree, wherever possible, to partner with local institutions (universities, NGOs, private research organizations, and civil society) to help build the skills, knowledge, and experience of local researchers and institutions, thus adding capacity that outlives the project.

Principle 5. Foster learning, sharing, and collaboration about evaluation. 
In conflict environments, rapid shifts in the flow of humanitarian aid, the rule of law, and levels of violence present challenges for even the most experienced researchers and program implementers. For those involved in evaluating media programs, these impediments to robust evaluation are compounded by the constantly evolving global media landscape and the resulting changes in the media ecologies of even the remotest countries. Given the unique challenges facing those involved in media interventions in conflict environments, collaboration and the sharing of research findings are essential. Sharing research findings and lessons learned both within and across organizations helps avoid the duplication of mistakes and maximizes the efficient allocation of the all-tooscarce human and financial resources available for evaluation. In support of this culture of learning, supporters of the Caux Principles agree, wherever possible, to do the following:

- As appropriate and where it does not threaten the safety and security of research subjects or researchers, share with other actors their monitoring and evaluation reports, lessons learned, data, and best practices.

- Generate recommendations on both project and policy level and circulate these to others involved in related efforts.

Principle 6. Embedded evaluation into the entire project's life cycle and beyond To optimize impact and efficacy, evaluation should inform every phase of project execution, beginning with the design phase including the implementation and evaluation phases and, where possible, follow-up evaluations well after the project's completion. Accordingly, supporters of the Caux Principles agree, wherever possible, to do the following: 
- When project funding and timing allow, come to an explicit agreement about the evaluation plan before a contract is signed. This includes identifying and agreeing on (a) baselines against which project success will be gauged; (b) inputs, activities, proposed outcomes, indicators of success, and supporting methodology; and (c) the roles and responsibilities of each party involved.

- Identify and define the overarching project goals and sets of assumptions (i.e., theories of change) that link program activities to intended goals at the projectplanning phase. This includes developing clearly articulated research questions that disaggregate individual level objectives (e.g., reaching a particular audience) from societal-level objectives (e.g., promoting freedom and democracy).

- Begin each project with a monitoring plan based on a logical framework that includes baseline data, activities, outputs, data source(s), and frequency of data collection, as well as process and outcome indicators.

- Monitor all media project activities during the implementation phase to test whether they are effective.

Good M \& E can offer helpful insights regarding project design and implementation strategies and uncover changes that may need to be made. Embedding evaluation into the execution of a project can also create a valuable feedback loop that improves the conduct of project activities as well as future project planning. To get the most value from evaluation, Caux signatories should, wherever possible, do the following:

- Encourage interactions between donors, implementers, and researchers throughout the project cycle.

- Incorporate an ongoing review process in the project plan, recognizing that 
monitoring results, evaluation results, and environmental considerations may necessitate changing how project goals are measured — and even the project goals themselves.

- Design research frameworks that measure unexpected or unintended results. This may include incorporating mixed methods, counterfactuals, control groups, experimental methods, or randomized controlled trials.

- Consider using multiple methods to cross-verify findings and test causal links. Principle 7. Promote realistic evaluation practices

Because stakeholders are often under pressure to demonstrate a program's efficacy, evaluation plans are often designed to maximize positive findings in the interest of continued funding streams. But measuring media effects is difficult even in the most controlled environments, and establishing causal links between program activities and outcomes is particularly challenging in conflict environments. Donor organizations must be aware of - and implementers must be forthright about — what can realistically be achieved and measured. Supporters of the Caux Principles, therefore, agree, where possible, to do the following:

- Actively educate all stakeholders involved - including donors, implementers, and methodologists - about what a project can and cannot achieve, and what can and cannot be measured through evaluation.

- Understand the validity of a specific project's theory of change, include both short- and long-term evaluation components.

Principle 8 . Work to promote greater clarity surrounding evaluation The time necessary to navigate complex and unclear reporting requirements is a 
luxury that those working in rapidly shifting conflict environments can ill afford.

Implementers struggle to understand and fulfill the expectations of their different funders. Greater clarity of terminology is needed. Overused jargon and misused terminology often undermine evaluation practices. Terms need to be clarified and standardized across the community of practice involved in evaluation. Developing a better understanding of how to conduct more effective media interventions in conflict is the responsibility of all parties involved. Accordingly, the Caux Principles affirm that evaluations, where possible, should do the following:

- Adhere to the glossary of terminology outlined by the more general guidelines for evaluation developed by the Organization for Economic Co-Operation and Development, Development Assistance Committee Guidelines.

- Work toward common intra- and inter-organizational codes of practice, vocabularies, and evaluation requirements across departments and bureaus.

Clearly distinguish project outcomes from impact. Caux delegates believe that outcomes (immediate project-related goals) and impact (long-term consequences, which can be intended or unintended) are often conflated. This definitional confusion can present a major challenge for those working in evaluation.

\subsection{Summary and Reflections}

In this chapter I have argued that media assistance needs to be specifically tailored to meet the needs of conflict and post-conflict settings. As mentioned in chapter one, media's role in conflict-ravaged societies is to make sure that accurate information reaches the population, as opposed to politically coloured information or harmful 
propaganda. In post-conflict-societies media assistance has an altered, more complex role than in conflict settings, supporting peace-building and democratization processes, including making sure that reporters are able to practice objective journalism, media outlets are independent, and that there is a legal framework that supports this independence. Except for these general similarities within conflict and post-conflict settings, one should also remember that every conflict and post-conflict setting has its own specific context and challenges.

I have also discussed the specific issues facing those working with assessing media interventions in conflict settings and media assistance in post-conflict societies. There are numerous challenges: varying terminology and unrealistic expectations among donors; lack of funding, time or planning among the media NGO's designing and implementing media assistance programs; and specific in-the-field challenges, where security and safety affect general logistics and data collection. The discussion of these challenges provided background and context to better understanding what inspired the organizers of the Caux Conference.

The conference resulted in a set of eight principles, The Caux Guiding Principles, a sort of road map for how to improve the process of monitoring and evaluation of media assistance. They encompass the challenges mentioned in this chapter and offer solutions in a clear and comprehensive manner. They are practical and easy to integrate in an organizations policies and practices.

Furthermore, it is noteworthy that the principles are a result of how key players together discussed how to best improve the field, thus expressing a collective will to focus on the specific issues, and also conveying a belief in the applicability of the 
principles. In short, the Caux Guiding Principles express a commitment from those who formulated them.

Arsenault, Himelfarb and Abbott, suggest four steps of how to continue the process started at the Caux conference: (i) that the Caux Principle be adopted and applied, (ii) that a stakeholders regularly meet up and discuss best practices, (iii) that a community of practice be established around research concerned with sharing and learning from each other, and, (iv) that donors engage in a continuous dialogue with researchers and implementers alike (28-29).

These suggestions sparked my curiosity, and guided me to the focus of this thesis, to investigate if the parties followed through with their commitment and realized the four steps. As part of my research, I contacted participants of the Caux Conference to assess whether the conference has caused the intended change, of creating a community of practice and establish a consensus around how to improve monitoring and evaluation. In the next chapter, I will present and analyze the answers received as part of my research; interviews conducted with individuals working at some of the organizations that participated in the Caux Conference. I hope that my findings, as discussed in the next chapter, along with the background context provided in this chapter, will help illuminate the current state of play of assessment methodology. I also hope that it will shed some light over the issue of cooperation between the different actors in the sector of media assistance in conflict and post-conflict societies. 


\section{The Caux Conference: Its Principles, Impacts and Legacy}

\subsection{Introduction}

To understand the impact and legacy of the Caux Conference, it is important to first situate it in its proper context, as part of a larger trend in development and democratization. Therefore, I begin this chapter with a brief account of the context of the Caux Conference. As mentioned in the last chapter, the Caux Conference resulted in the Caux Guiding Principles, a set of comprehensive advice on how to professionalize the field and improve communication and relations between the different parties, or stakeholders, involved in various aspects of media assistance.

Most of the rest of this chapter is spent examining the impacts and legacy of the Caux Conference and the Caux Guiding Principles. Are the Caux Guiding Principles adopted and applied? Do stakeholders regularly meet up and discuss best practices? Is there an established community of practice engaging in sharing and learning from each other about assessing media assistance? Are the donors engaged in a continuous dialogue with scholars and practitioners?

These questions are based on the recommended follow-up steps of Arsenault, Himelfarb and Abbott. To find answers, I contacted as many participants as I could find viable contact information for. It turned out to be 15 of the 30 organizations and participants involved in the 2010 Caux Conference. Originally I received some kind of answer from 10 of them, and, eight were positive to being interviewed. In the end, however, because of unknown reasons, only six agreed to participate. 
Three out of the four who did not participate in the formal interviews chose to provide background information and some documentation, such as working papers, introductions of speakers, and the program of the conference, via email. One of the three engaged in an informal interview. Part of the documentation and information retrieved, have served as research material for this thesis, for example, the list of participating organizations.

As the interviewees who participated in the formal interviews answered questions about their employer, and sometimes expressed opinions about their work, their employer, and the sector, I have chosen not to identify the interviewees by name so as not to risk compromising them. Rather, I have identified them by their affiliated organizations. However, it is important to note that their views may not necessarily reflect the positions of their organizations.

The goal with the interviews was to find out if the Caux Conference has had an impact on the various stakeholders, and if the Caux Guiding Principles have been adopted and are actively being used. My research shows that the majority of the interviewees express the view that the Caux Conference was a great initiative, but that it had a limited impact, if any. The interviewees suggest that the main reason for this is the lack of a rigorous follow-up process involving all of the Caux Conference participants. They also identify that a driving force, or "a motor" is key to driving this type of information forward; there needs to be someone who keeps calling everyone back to the round table for continued discussions. In the case of Caux, this motor fizzled.

However, the interviews also demonstrate that the Caux Guiding Principles have become a document of reference in certain situations, for example when designing new 
projects and programs. One of the six interviewees, from Fondation Hirondelle, perceives the principles to be a living document, shaping the changes in the organization. It is worth noting that Fondation Hirondelle was one of the Caux Conference organizers, and participated in the two follow up conferences.

Overall, it appears that the Caux Conference is perceived as a welcome initiative of the past, but that all parties have moved on to new endeavours, which, may, or may not, be inspired by the Caux Guiding Principles. Regardless, the answers from the interviews shed some light on how the field is being professionalized.

\subsection{The Global Context to the Caux Conference}

The "Caux Conference," as it came to be called by the community that attended it, was not an isolated event. In fact, monitoring and evaluation of media development assistance had been on the agenda since the late 1990s. However, the major driving force behind creating the environment for the discussion was the global conference that produced the Paris Declaration on Aid Effectiveness.

The Paris Declaration on Aid Effectiveness, a document that was produced at the Second High Level Forum on Aid Effectiveness in 2005, was central to the increase in focus on improving monitoring and evaluation. It established, among other things, that "aid could - and should - be producing better impacts" (OECD.org). The consensus among the participating countries was that aid should be based on the experience of what works and that it should be divided into five pillars: "Ownership, Alignment, Harmonization, Managing for Results, and Mutual Accountability" (OECD.org). A few years later, in 2008, the participating countries of the Third High Level Forum on Aid 
Effectiveness endorsed the Accra Agenda of Action (AAA). The Accra Agenda for Action reaffirmed "the commitment to the Paris Declaration" and called "for a greater partnership between different parties working on aid and development” (OECD.org). Both the Paris Declaration and the Accra Agenda of Action were endorsed by a large number of nations (138 countries), international organizations and civil society organizations, and consequently sparked discussions and started processes on all levels of development, from government to grassroots levels.

The Paris Declaration created the environment for the community of donors, practitioners, and academics to meet in Caux in 2010, and to formulate the Caux Guiding Principles. For context, I will also mention a couple of other similar projects that were initiated during this period.

One example worth mentioning is the symposium "Planning, Monitoring, Evaluation in Media Development" that took place September 27-28, 2007, in Bad Honnef, Germany. ${ }^{17}$ The event was organized by “Forum Medien und Entwicklung," a network of German institutions and individuals, consisting of donors, academic researchers, program implementers, and monitoring and evaluation professionals, engaged in media development. ${ }^{18}$

${ }^{17}$ It is worth mentioning because it has been on the agenda at a global level, and because USAID mentions it in the report "Indicator Gap Analysis" (2010), as a project of interest.

${ }^{18}$ The organizations that cooperated for this particular conference were: the 
Among the participants and speakers were Andrew Puddephatt talking about the UNESCO Indicators and their tool kit approach, and Anna Godfrey presenting on how the BBC World Service Trust embeds research components into their project design. In addition to the general discussions about challenges in the field and exchanges of experience and best practices, the major outcomes of the conference were a working group, the Media ME expert group, and the idea of an online platform in the form of a wiki, for media monitoring and evaluation professionals to share tools and approaches of monitoring and evaluation (Jannusch 9).

The expert group is organized as a think tank and specialist advisory group (Comminit.com), and, according to the Cameco website, the group is active. The wiki is called Media ME and has been a work in progress since the initial conference in 2007. However, despite widespread discussions, including at global conferences such as the Global Media Forum in Bonn in 2008 and the Global Forum for Media Development in Athens the same year, there is no presence of the wiki online. Cameco provides information about the project, such as about the involvements of institutions such as the Annenberg School of Communications at the University of Pennsylvanian, USA, and the

Catholic Media Council (CAMECO), Deutche Welle Akademie, Friedrich Ebert Stiftung (FES), World Federation of Science Journalists (WFSJ), International Institute of Journalism (IIJ), Protestant Academy of the Rhineland, Center for Development Research (ZEF), and the Zurich University of Applied Sciences in Winterhur (ZHW). 
School of Journalism and Media Studies at Rhodes University, South Africa. Despite this, it appears that there has not yet been a formal launch of the wiki (Cameco.org). ${ }^{19}$ Another project worth mentioning, albeit of a different character, is the Media Map Project, initiated by Internews and the World Bank Institute in 2010, and funded by the Bill and Melinda Gates Foundation (Nelson and Susman-Pena 2). The Media Map Project is a comprehensive approach that aims to investigate the relationship between the media sector and governance, and the media sector and economic development, as part of a developing country's general development. In short, it is "analyzing the impact of media development assistance in specific contexts" (Nelson and Susman-Pena 2, Roy 4).

There are three different parts of the project. The first uses statistical data and econometrics to quantify the relationship between media and development, the second examines cases of media development assistance in eight countries, and the third focuses on the donors, and how they assess their impact (Roy 4).

Despite being a pilot project, it has engaged the development sector in a discussion about media's role and relationship to governance and development, largely due to the network created around the project. In addition to the initiators, Internews, the World Bank, and the Bill and Melinda Gates Foundation, there are also institutions such as the Brookings Institute, Columbia University, New York, the University of Cambridge, UK, The Annenberg School of Communication at the University of Pennsylvania, Australian broadcaster ABC, The Wealth of Nations Index, and the

${ }^{19}$ I have contacted the person responsible at Cameco to find out the present status of the wiki without getting a response. 
Broadcasting Board of Governors were. In addition, the advisory board of the project had a wide variety of individuals representing institutions such as USAID and UNESCO among others (Nelson and Susman-Pena 2).

The Media Map Project produced a number of papers and cases studies, three overview papers, eight in-depth country case studies, papers on monitoring and evaluation of media development, and three literature reviews, as well as background material. All of these documents provide new and valuable information to the monitoring and evaluation community (Nelson and Susman-Pena 2). There is a website where all of the material is collected, and where 25 global datasets are made available to download (Nelson and Susman-Pena 2). Through its multi-facetted approach, the project is the most comprehensive one on media assistance to this day.

The Caux Conference was initiated during this same time period, in 2010, to develop and strengthen the community of donors, implementers, academic researchers, and monitoring and evaluation professionals. While the first conference had an international group of participants, the follow-up conferences were held in the United States and focused more on North American actors. This chapter examines what happened after the first conference in Caux, and looks at whether the Caux Principles have been adopted and commonly used by those who participated in the conference.

\subsection{The Caux Conference and After}

The subject of media in conflict zones had first come up as a discussion in 2008, at a meeting at the United States Institute of Peace (Fondation Hirondelle. Personal Interview. 28 Mar. 2014). The question was asked why money should be invested in media assistance in a conflict zone, when humanitarian assistance tends to be more 
pressing (Fondation Hirondelle. Personal Interview. 28 Mar. 2014). Practitioners of media assistance were asked about the relevant impact of media interventions. The discussion created the idea of organizing a seminar with focus on impacts (Fondation Hirondelle. Personal Interview. 28 Mar. 2014). The idea was to bring together key actors from the different communities involved in this field: donors, scholars, and professionals from the organizations implementing media assistance, to start a constructive dialogue (Fondation Hirondelle. Personal Interview. 28 Mar. 2014).

The conference that took place in December 13 to 17, 2010, was organized by the Center for Global Communication Studies at the Annenberg School of Communication at the University of Pennsylvania, The Broadcasting Board of Governors, Fondation Hirondelle, Internews, and the United States Institute of Peace. Key actors from Europe and North America were present (a list is presented in table 3). The goal of the conference was to "develop a shared set of approaches and best practises for identifying the role that media and information programs can and do play in conflict and post conflict countries" (Arsenault, Himelfarb and Abbott 30). 
Table 3. Participating Organizations at the Caux Conference, December 2010

(Arsenault, Himelfarb and Abbott 30,31).

Annenberg School of Communication

Audiovisuel Extérieur de la France

BBC Global News

BBC World Service Trust (now BBC Media Action)

Broadcasting Board of Governors

Centre for International Media Assistance

D3 Systems

Office of Communications at US Central Command

Deutsche Gesellschaft für Internationale Zusammenarbeit

Deutsche Welle

Development Impact Evaluation initiative, World Bank

Development communication consultant

Fondation Hirondelle

German Federal Foreign Office

Graduate Institute in Geneva

Institut de Reserche Empirique en Economie Politique

Institute of Applied Media Studies

International Research and Exchanges Board

InterMedia

InterNews Network,

International Crisis Group

Media Development Consultants

Media Support Solutions

Office of Transition Initiatives, USAID

Open Society Foundation

Press Now

Search for Common Ground

United Nations Department of Public Information

United States Institute of Peace

University of Oklahoma

The conference organizers goals were to start a process and build a community. A Caux Guiding Principles event and two more conferences were organized to follow up the one in Caux. The location of the other two conferences was the United States Institute of Peace in Washington DC. According to some of the participants I interviewed, the 
change of location limited the level of participation from Europe (Independent media development consultant. Personal interview. 18 Mar. 2014).

Since the group of participants did not stay the same after the initial gathering, I decided to focus on the original group of participants, and investigate whether they proceeded to use the Caux Guiding Principles and build on the relations that were established. Some of the participants I interviewed also participated in the follow-up conferences. Others have since changed positions or left the organizations they represented. In those instances, I have had to complement their interviews with further information from the organization.

The organizations that I was able to contact and that agreed to participate in this study are: the BBC Media Action, formerly known as BBC World Service Trust (the BBC's development charity), Fondation Hirondelle (a Suisse media NGO), Internews (an American media NGO), IREX (an international media NGO with main offices in Washington DC, US), the University of Oklahoma, and an independent media development consultant.

$\mathrm{BBC}$ Media Action is a well-rounded organization, running programs and projects in various parts of the world, as well as conducting its own research on media assistance and its impact. Fondation Hirondelle, Internews and IREX are primarily organizations that design and implement media assistance programs and projects. All four organizations receive funding from donors and volunteers for their programming.

The scholar from University of Oklahoma is a professor in strategic communication, but also assesses media assistance projects, and trains media NGO professionals in monitoring and evaluation methodology. The independent consultant is a 
former journalist engaged in conducting monitoring and evaluation, as well as report writing. Together, these six participants represent a cross-section of the participants at the Caux conference.

\subsection{The Interviews: Summary and Analysis}

I have organized my summaries and analysis of the interviews along the lines of the recommendations on how to move on after the conference, as made by Arsenault, Himelfarb and Abbott in the report "Evaluating Media Interventions in Conflict Countries: Toward Developing Common Principles and a Community of Practice". For valuable information received that does not fit into any of the four categories, a fifth is created under the subtitle "Other Findings".

The recommended four steps are: that the Caux Guiding Principles be adopted and applied; that stakeholders regularly meet up and discuss best practices; that a community of practice is established around research concerned with sharing and learning from each other; that donors are engaged in a continuous dialogue with researchers and implementers alike (Arsenault, Himelfarb and Abbott 28-29). I have reformulated these recommendations into questions that provide a structure for my research. The questions and the discussion follow below.

\subsubsection{Are the Caux Guiding Principles adopted and applied?}

This question does not have a simple answer. For some, the Caux Guiding Principles have had significant and obvious impact and influence, but for others the principles have not had much effect. 
According to the interviewee from Fondation Hirondelle, the conference and the resulting principles were something of a game changer. Being part of the initiating team, the organization was interested in getting as much out of the process as possible. They were also part of the follow-up events. The result of their efforts has included: an increased awareness in the organization about the importance of terminology along the lines of Principle 8, "Work to Promote Greater Clarity Surrounding Evaluation"; a change in assessment of projects and programs corresponding to Principle 6, "Embed Evaluation into the Entire Project's Life Cycle and Beyond"; and making sure that some of the project budget is set aside for monitoring and evaluation, which corresponds to Principle 1, "Expand Financial Support for Evaluation of Media Interventions in Conflict Countries" (Fondation Hirondelle. Personal interview. 28 Mar. 2014).

According to the Fondation Hirondelle interviewee, they "are very careful now about the words used: 'impact', 'outcome', 'effect', and 'result,'” (Fondation Hirondelle. Personal interview. 28 Mar. 2014). As mentioned in chapter four, it is problematic for assessment professionals and scholars that media NGOs and donor agency administrators did not distinguish between the different terms, since it becomes difficult to understand what should be measured and how. Learning to distinguish when to use which term makes it more clear what the intentions are of specific projects, and facilitates the monitoring and evaluation of projects. 
Regarding changes in assessment practices, Fondation Hirondelle is, among other things, more careful now to collect baseline data at the beginning of every project, as they are more aware now that baseline data is necessary to measure change during the implementation of a project, as well as after it is concluded (Fondation Hirondelle. Personal interview. 28 Mar. 2014).

According to the Internews interviewee, the Caux Conference led to a shift of the organization's approach to assessment. There is now a certain "Caux-based" thinking to some of the approaches that have been, and are being, developed. For example, more sophisticated and refined methodology is used for assessment, such as focus groups, and there is an improvement in developing a practise of using results chains such as logical framework matrixes at an early stage of project design. (Internews. Personal interview. 26 Mar. 2014).

As mentioned in chapter four, using a logical framework matrix helps the project designer to clearly formulate the process of cause and effect in a project, the intended results formulated as outcomes, and the desired long-term impact on higher-level goals, such as changes in attitude or raising awareness. Formulating intended outcomes forces the project designer to also formulate how to measure this outcome throughout the project, using progress indicators (discussed in chapter two).

Furthermore, according to the interviewee, The Caux Guiding Principles have become a document that Internews uses as a best practices framework when designing and proposing new projects and programs (Internews. Personal interview. 26 Mar. 2014). This means that the principles are used to show donors that Internews tries to follow and apply the Caux Guiding Principles. 
Fondation Hirondelle and Oklahoma University also use the Caux Guiding Principles in a similar manner, as a document of reference and best practices, when concerned with assessment in conflict and post-conflict settings, according to the interviewees from respective institutions. (Fondation Hirondelle. Personal interview. 28 Mar. 2014.; Oklahoma University. Personal Interview. 28 Mar. 2014).

IREX is presently is going through a major process of improving its assessment protocol and practices. However, the interviewee could not tell whether it had anything to do with the Caux Conference or the Caux Guiding Principles or not. (IREX. Personal interview. 20 Mar. 2014). Nevertheless, the improvement process entails such changes as new organizational guidelines and policies. For example, the practice of including logical framework matrixes in all projects is being introduced, which corresponds to Caux Guiding Principle 6 (IREX. Personal interview. 20 Mar. 2014).

According to the IREX interviewee, logical framework matrixes have many benefits. For example, they bridge the gap between a project's designers and monitoring and evaluation professionals, because the force designers to think about intermediary results and to cooperate with the assessment professionals on how to measure them. "It creates understanding of change, and how that change happens" (IREX. Personal interview. 20 Mar. 2014).

Furthermore, IREX now spends 3-5 percent of their total budget for evaluation, which corresponds to Caux Guiding Principle 1. Also, new assessment tools have been developed, some with the help of scholars who were present at Caux. For example, tools 
relating to measuring impacts. This corresponds to Caux Guiding Principle 3 (IREX. Personal interview. 20 Mar. 2014).

Furthermore, IREX has created a new position, responsible for creating an institutional memory, which until now has mostly existed in the form of "spreadsheets with data that isn't being used because we don't have time to analyze" (IREX. Personal interview. 20 Mar. 2014). The responsibilities of this new position include data collection, analysing results, and creating documents of best practises and lessons learned (IREX. Personal interview. 20 Mar. 2014). This corresponds to Caux Guiding Principle 8, "Work to Promote Greater Clarity Surrounding Evaluation," the part of the principle regarding the processes within organizations (Arsenault, Himelfarb, and Abbott 27,28). Considering the examples mentioned above, even though IREX may not explicitly or consciously use the Caux Guiding Principles as a living document, the organization still seems to be implementing, or is at least acting consistent with, some of the principles, (Internews. Personal interview. 26 Mar. 2014).

The BBC Media Action was in many ways ahead of Fondation Hirondelle, Internews and IREX. They already had a group committed to research on impact, monitoring and evaluation methods. They also already had part of their project and program budgets committed to monitoring and evaluation. They also place the Caux Conference within a larger debate concerning evidence of the impact of development projects that they were, and are, following and participating in. As such, the interviewee from BBC Media Action does not see an explicit causality between the Caux Conference and how it proceeded. However, the interviewee did see the conference and the creation 
of the Caux Guiding Principles as a confirmation that BBC Media Action was headed in the right direction (BBC Media Action. Personal interview. 7 Apr. 2014).

From the perspective of an organization involved in research about the field, and helping media NGOs developing assessment tools, Oklahoma University’s scholar argues that it is difficult to claim causal effect between the Caux Conference or the Caux Guiding Principles and the changes in how media NGOs assess and report the result of their projects and programs. Instead, the scholar argues that the causal factor is that the donors are asking for enhanced reporting, and that the NGOs have interpreted this as enhanced monitoring and evaluation the impacts and effectiveness projects and programs (Oklahoma University. Personal interview. 28 Mar. 2014).

\subsubsection{Do stakeholders regularly meet and discuss best practices?}

Stakeholders in this context are the different camps involved, that is, donors, NGOs, IGOs, scholars and assessment professionals. According to all parties interviewed, stakeholders in general do regularly meet and discuss best practices, but not in the forum of the Caux process, or concerning the Caux Guiding Principles. The Caux Conference is perceived to have been a welcome opportunity for discussion, but it did not establish a forum for regular meetings or create an official community of practice. The interview from Oklahoma University observes that there was momentum for only about a year after the conference (Oklahoma University. Personal interview. 28 Mar. 2014).

There are, however, other conferences, regional and global, as well as specific collaborations around common themes and research projects, even though they do not have the same focus as the Caux Conference did. Several of the interviewed parties 
explain that there are issues of common interest being addressed both in the media development community and within the assessment community, for example, the improvement of monitoring and evaluation was high on the donor agenda at the time, and so was media assistance. Now, according to the IDP and interviewee from IREX, the monitoring and evaluation community is more interested in storing and visualizing data, rather than improving indicators and tools, while donors are more interested in the relationship of media and governance (Independent consultant. Personal Interview.18 March 2014; Internews. Personal Interview.26 March 2014; IREX. Personal Interview.20 March 2014).

Furthermore, all interviewees state that their organizations have attended conferences on related subjects of impact. For example, there was a conference that sprung out of the Caux Conference, with a focus on using content analysis as a method of measuring change. Last year, several of them, including BBC Media Action, Hirondelle and the Annenberg School of Communication, were invited to a yearly broadcaster conference called CIBAR, where they discussed the research they are engaging in. For example the BBC Media Action shared its research on what constitutes evidence in the media sector, and their approach to audiences, and how it can be shared with the broadcaster sector in the future (BBC Media Action. Personal Interview. 7 Apr. 2014; Fondation Hirondelle. Personal Interview. 28 Mar. 2014).

All parties interviewed in this study express a certain disappointment that the process started in Caux did not develop as planned, for example, the fact that there has not been a yearly conference to follow up, assess and discuss the impact of the Caux Guiding Principles. Another disappointment that was discussed was that they never 
reached consensus on what frameworks and methodologies to use in conflict and postconflict settings.

Despite this, they all think it was a good initiative and a great opportunity that touched on many important issues in the sector. They all mentioned that it would be interesting to meet with everyone again and compare notes (BBC Media Action. Personal Interview. 7 April 2014. Fondation Hirondelle. Personal Interview. 28 March 2014. Independent Consultant. Personal Interview. 18 March 2014. Internews. Personal interview. 26 March 2014. IREX. Personal interview. 20 March 2014. University of Oklahoma. Personal Interview. 29 Mar. 2014).

\subsubsection{Is there an established community of practice engaging in sharing and learning from each other about assessing media assistance?}

According to all parties interviewed, there is a community of practice, although, not necessarily a formally established one. The $5^{\text {th }}$ of the Caux Guiding Principles, "Foster Learning, Sharing, and Collaboration about Evaluation," is not as obviously followed, as the interviewees would want. However, some of the connections made at the Caux Conference have persevered and solidified, both formal and informal ones. For example, some of the NGOs hired some of the scholars to help develop new assessment tools, and the BBC Media Action commissioned scholars to do a literature review of methods used to measure impact in development (BBC Media Action. Personal Interview. 7 Apr. 2014; Internews. Personal interview. 26 Mar. 2014; IREX. Personal interview. 20 Mar. 2014). 
There is a network in place, and however slowly, a more organized community seems to be developing. New collaborations are being initiated between the original participants and with universities, scholars and institutes, thus expanding the (informal) community. New indicators are being developed, new methodologies explored, and new research projects are initiated. For example, Fondation Hirondelle has approached the Harvard Humanitarian Initiative and the Carr Center at Harvard, for a common long-term project, a web platform on transitional justice. The project has a dual aim: to provide a platform of unbiased information about transitional justice issues from different countries to journalists and the general public globally, and to serve as a type of early warning system for conflict (Fondation Hirondelle. Personal interview. 28 Mar. 2014).

Furthermore, this collaboration between Fondation Hirondelle and Harvard potentially opens up new avenues of funding, as well as possibilities to strengthen the field by providing new academic research (Fondation Hirondelle. Personal interview. 28 Mar. 2014). Both issues are of great importance for the sector: funding is a constant challenge, and strengthening the field increases both credibility and the chances of more funding.

The IREX interviewee's perception is that although media NGOs are increasingly engaged in monitoring and evaluation, there is no organized group of sector specific professionals. (IREX. Personal interview. 20 Mar. 2014). In comparison, monitoring and evaluation professionals, in general, and in development especially, have established associations where they meet and discuss hot topics, issues and best practices. One example is the American Evaluation Association (AEA), and another is the International Development Association (IDA). 
The IREX interviewee argues that part of the problem is, and has been for a long time, that assessment is conducted by former journalists rather than by monitoring and evaluation professionals. The interviewee from Internews argues along similar lines, namely, that many former journalists join the media NGOs as assessment professionals, without having the necessary academic or professional background to be able to properly conduct monitoring and evaluation. The interviewee suggests that it is an endemic problem that affects the whole sector of media assistance, not just their organization (Internews. Personal interview. 26 Mar. 2014; IREX. Personal interview. 20 Mar. 2014). It should be noted, according to the interviewees from Oklahoma University and Inernews, that there is some exchange between development sectors. Some of the monitoring and evaluation professionals from other development sectors are being recruited into media assistance, and some of the professionals in media assistance are members of the AEA and IDA. However, what all interviewees argued, was, that it would be helpful to the sector if the media assistance community had their own platform or organization (Internews. Personal interview. 26 Mar. 2014).

Another problem of the media assistance sector is that NGOs are essentially competing with each other for funding. Thus, sharing data or information about best practices is not always perceived as the strategic thing to do. The scholar from Oklahoma University argues that, four years after the conference there is still no real sharing of data, or an official forum for sharing data.

According to the scholar and the Independent Consultant, there are different reasons for this according to some of the interviewees; one reason is that no one wants to share the flaws and failures of their programs, since funding is dependent on their 
success; a second is that data is proprietary; a third is that there is little or no institutional memory, which in turn means that there is no structured way of storing and keeping records. (University of Oklahoma. Personal Interview. 29 Mar. 2014; Independent Consultant. Personal Interview. 18 Mar. 2014).

However, according to the interviewees from the media NGOs, the issue of competition is not very grave. The interviewee from Fondation Hirondelle believes that collaboration is preferable, especially concerning defining criteria and setting similar standards for monitoring and evaluation. It would make the media NGOs more efficient, and simplify communication with donors (Fondation Hirondelle. Personal interview. 28 Mar. 2014).

According to the Internews interviewee, Internews tries to collaborate with their counterparts in the sector as much as possible, especially at the design stage, since it increases the chances of receiving complementary funding. (Internews. Personal interview. 26 Mar. 2014). Furthermore, the IREX interviewee also expresses a wish for increased collaboration with its counterparts, such as Internews, especially sharing experiences on what works in terms of project design and assessment processes and tools (IREX. Personal interview. 20 Mar. 2014).

\subsubsection{Are the donors engaged in a continuous dialogue with scholars and practitioners?}

The different organizations have had different experiences regarding dialogue with the donors. According to the interviewee from Fondation Hirondelle, the organization's experience is that the dialogue with donors has improved somewhat, but 
that donors still have unrealistic expectations in terms of demonstrating impacts (Fondation Hirondelle. Personal interview. 28 Mar. 2014).

The Interviewee perceives that there is still pressure from donors to show how media assistance projects have an impact on ultimate goals such as reducing violence in a society, or strengthening peace, while the time and funding to conduct this type of evaluation is fairly limited. Therefore, the interviewee argues, the organization is more careful distinguishing between outcome and impact early on in a project's life, and focuses on measuring outcomes instead of impacts (Fondation Hirondelle. Personal interview. 28 Mar. 2014). As established in chapters two and three, outcomes are measured shortly after an intervention is done. However, the organization expresses an interest in measuring more long-term impacts, when donors express interest and provide funding, and when the conditions allow for the needed methodology (Fondation Hirondelle. Personal interview. 28 Mar. 2014).

According to the interviewee from Internews, the media NGOs seem more interested in discussing and improving assessment practices than donors and big intergovernmental organizations like the UN. The Caux conference probably had the least impact on donors, according to the Internews interviewee, partly because there were only two donor agencies represented, Germany and the United States. The Internews experience is that donors are still more interested in quantitative data related to performance indicators, which, as mentioned in chapter two, have a tendency to oversimplify a complex reality and do not measure the quality of intervention or assistance (Internews. Personal Interview. 26 Mar. 2014). 
However, the Internews interviewee argues that Internews "has developed a new confidence towards donors", and that the organization is "not afraid to share the knowledge that individual projects do not change the world" (Internews. Personal Interview. 26 Mar. 2014). Instead of showing how their projects create a change, they focus on showing donors how their projects and programs are contributing factors to higher-level goals such as conflict mitigation or peace building. (Internews. Personal Interview. 26 Mar. 2014).

The IREX interviewee is wary of how much the donors set the agenda of monitoring and evaluation in the field of media assistance. The interviewee argues that it would be better if the initiative to change practices and increase focus on assessment came from within IREX, or if the changes were formulated more in a dialogue between donors and media NGOs. According to the interviewee, many of the changes in IREX's assessment protocol and practice are a response to donors' demands (IREX. Personal Interview. 20 Mar. 2014).

The interviewees from BBC Media Action are of the view that donors are pressuring everyone in the sector to show what works. They observe that there is, and has been, an increased drive towards evidence-based policy-making. This means that donors are increasingly interested in basing policy on evidence of what has worked in the past. According to the $\mathrm{BBC}$ interviewee, this is a dialogue that started before the Caux Conference, and is linked to the economic downturn in 2008. After the downturn, governments collectively put greater pressure on donor agencies to give account of where 
the allocated funds go, as well as of what impact the invested funds have (BBC Media Action. Personal Interview. 7 Apr. 2014).

The independent consultant (IPD) has an alternate explanation for the change of focus and terminology, suggesting that this is part of the general trend in development of donors demanding demonstration of results and that this trend is being felt in the area of media assistance as well. The IPD also points out that media assistance is a small sector that goes in and out of fashion. Therefore, it is a challenge for the media NGOs to stay in the donor spotlight (Independent Consultant. Personal interview. 19 Mar. 2014).

\subsubsection{Media NGOs and Academia}

In an article titled "Measuring the impact of media assistance programs: perspectives on research-practitioner collaboration", Susan Abbott and Maureen Taylor argue for an improved cooperation between researchers and practitioners, and how this can be done by collecting and standardizing tools, and adapting them to what they are supposed to measure and evaluate. The goal of the suggested collaboration is to professionalize the field.

According to the interviewed parties, it seems that media NGOs and researchers have increased collaboration. I have mentioned some examples of this under the subheadings concerned with stakeholders and a community of practice. IREX and Internews have cooperated with some of the academic institutions present at the Caux Conference, developing tools specifically tailored for conflict and post-conflict settings, such as tools for content analysis, or focus group interviews. The media organizations especially appreciate the tools developed for content analysis, since they show a real 
change in a tangible way, by providing, for example, information on how many articles about post-conflict elections are written in balanced way, or according to the training the local journalists received through a media assistance project (Internews. Personal Interview. 26 Mar. 2014; IREX. Personal Interview. 20 Mar. 2014).

Another example is Fondation Hirondelle, and how it approaches academic institutions such as Harvard, pursuing joint long-term research projects Fondation Hirondelle. Personal interview. 28 Mar. 2014). There is also the example of the BBC Media Action commissioning the University of Oklahoma to do a literature review of academic articles about evidence - what it is and how to collect supporting data, in order to better understand their own work and what they can contribute to the sector (BBC Media Action. Personal Interview. 7 Apr. 2014).

Thus, the Caux Conference seems to have contributed to bridging mutual suspicion between researchers and practitioners, and has also contributed to opening a venue for closer collaboration between the two camps. Both sides are less wary of approaching the other. On the contrary, they seem to seek each other out for mutual benefit.

It seems that the major media NGOs in the sector, such as BBC Media Action, Fondation Hirondelle, IREX and Internews are the driving forces for improvement of both methodology and practice. This may be because it is in their interest to improve their work as in order to continue to receive funding. The reality is that their very existence is at stake if they cannot show the positive results of their programs and projects. Hence, collaborating with researchers, with academia, and other similar institutions, does not only solidify the credibility of media NGOs, it also opens up new venues of funding. 
For academic researchers, there is an opportunity to explore and develop a new field, as well as related hot topics, and to provide valuable policy recommendations to governments.

\subsection{Observations}

The interviews show that the participants of the Caux Conference were excited about the opportunity to meet such a broad spectrum of stakeholders operating in the field of media assistance and intervention, and discuss challenges and future needs. However, they also show a certain disappointment at how a promising beginning was not entirely followed-up. According to the overall impression of my interviews, Caux did not become the institution needed, or give answers to the "million dollar questions" of assessing media interventions in conflict and post-conflict settings. In fact, according to most of the interviewees, it did not have much of a direct impact.

However, in spite of the expressed views of the interviewees, when looking at what the organizations are doing, it is difficult to say that the conference did not have any impact. For example, according to the interviewee from Fondation Hirondelle, among other things, they are now better at allocating part of the budget for monitoring and evaluation, which corresponds to the first Caux Guiding Principle; and they are building more and better relationships with scholars and academic institutions such as Harvard University.

The interviewee from Internews told of a Caux-based approach to monitoring and evaluation, which allows them to get better at gathering data while a project or program is being implemented, which corresponds to the sixth principle, "Embed Evaluation into the 
Entire Project's Life Cycle and Beyond". IREX also reflects principle six, in its recent approach of formulating a logical framework matrix at the designing stage of every project or program.

Therefore, although there was never an official follow up of the Caux Guiding Principles to determine to what extent they were implemented, it is still arguable that they have, nevertheless, left a mark, as some of their original objectives seem to have been fulfilled.

I would argue that there has been a shift in awareness and practice since the Caux Conference, even though it is difficult to ascribe this change to the conference as an isolated incident.

Mainly, what seems to have occurred is a realization of how the notion of "impact" was interpreted differently by every organization present, and sometimes even within organizations. This in turn, led to a growing insight about what needed to be done in terms of defining impact, developing assessment tools such as indicators and methodology, and the need to keep up a constructive dialogue over time, as well as active cooperation between the different levels: donors, implementing organizations, scholars and assessment professionals. The Caux Guiding Principles reflect this awareness, and provide advice on how to improve the situation.

My impression is that assessment of media assistance is still seen as a relatively new priority among the media NGOs, and as something that is forced from above, from the donors. The donors want results; therefore, the organizations are scrambling to show good results in order to keep getting funding for projects. However, showing impact has turned out to be harder than anticipated, and taken more of an effort. Interestingly, the 
effort is changing the field, and improving it, especially through the use of logical framework matrixes, and the increased collaboration with academic institutions.

Furthermore, the changes seem to occur in a somewhat organic process. The group of stakeholders is very diverse (including media NGOs, IGOs, donors, academic institutions, and even consultancies) and is also part of the larger context of development. This means that they operate in settings other than just conflict and post conflict societies, and often engage in more sectors than media assistance. This "spread", or flexibility of the actors, poses a challenge to get everyone to commit to cooperation on a specific issue, even to a comprehensive and hands on document like the Caux Guiding Principles. Some of the interviewees called for "a motor", an individual or a secretariat that would keep pushing the process forward. However, until now, no single organization has taken on this role, which, according to the interviews is a result of a lack of time and resources. Perhaps the media NGOs involved in media interventions and media assistance are experiencing the growing pains of a relatively new sector, a sector that has managed to operate under the radar for a while, without having to prove its worth. The fact that it is now being pressured to demonstrate its value and contributions and is rising to the challenge can be viewed as a process of professionalization and the raising of the sector to a new level of operation. If the Caux Conference contributed anything, it was to put assessment of media projects and programs in conflict and post-conflict settings on the agenda, and thus contribute to the process of making monitoring and evaluation more mainstream within its sector. 


\section{Conclusion and Implications}

In chapter five, I discussed whether the Caux Conference has had an impact on the organizations that participated. Interesting information emerged from the interviews that shed light on the development of media assistance assessment, and on collaboration between the various stakeholders.

There have been some positive accomplishments, but there are also some remaining challenges. For example there is improved collaboration between practitioners and scholars concerning research. The practitioner relationship with donors is, however, still marred by frustration over unrealistic expectations and lack of dialogue.

Some of the findings in chapter five provide answers to the four questions asked in the introduction of this thesis. However, I will now answer the four questions more directly, drawing upon research from throughout the thesis. I hope that this study, with its focus on the Caux Conference and the Caux Guiding Principles offers some new insights to aid in the professionalization of the media assistance sector and how it conducts assessment of programs and projects in conflict and post-conflict settings.

\subsection{What Is Being Done to Professionalize the Field?}

The window of opportunity that opened up with the Paris Declaration created a climate of discussion and self-reflection among stakeholders, and opened up space and opportunity to bring stakeholders together at Caux and other venues. The 2010 Caux Conference itself triggered valuable discussions that were continued within and between organizations. The attending parties, a group of 30 key stakeholders in the field of media development, formulated and agreed upon the Caux Guiding Principles, Although no 
formal follow-up to the principles and their implementation has occurred, they have, in fact, informed and influenced the process of improving the policy and practice of assessment in some of the media NGOs that participated in the Caux Conference. As discussed in chapter five organizations are introducing new internal structures and procedures concerned with the assessment of output and impact. For example, three of the six media NGOs interviewed for this thesis participated in a workshop that developed tools of content analysis, specific for conflict and post-conflict settings.

Furthermore, IREX has established a new position, a role focusing on building institutional memory, including inspecting how evaluations are done and improving on how data is stored and used. Internews has improved the practise of including proper results chains such as logical matrixes (the importance of which was discussed in chapter four) at an early stage of project and program planning. Fondation Hirondelle invests more of its budget on both internal and external monitoring and evaluation of projects, and uses qualitative research methodology as well as quantitative. BBC Media Action has expanded its research group, and makes sure to have researchers placed on location.

Another aspect of professionalizing the field is the increased collaboration between media NGOs and academic institutions. Developing assessment tools based on social science research methodology improves credibility, and also helps with some of the issues mentioned in chapter two, like reliability and validity.

However, the missing party in this discussion seems to be the donors. To truly professionalize the field in a multi-party discussion, the donors need to further engage with the other parties in the ongoing dialogue of how to improve the sector. At the time of writing, there is no research showing why donors are not more fully engaged. 
The report “Mapping Donor Decision Making on Media Development", produced by Alcorn et. al. within the frame of the Media Map Project, is the only substantial report about donors' interest and demand on improved monitoring and evaluation within the media development sector. It shows that donors have increased their emphasis on monitoring and evaluation during the past two decades for three main reasons: (i) governments demand greater accountability; (ii) monitoring and evaluation shows impact and legitimizes work; (iii) monitoring and evaluation provides opportunity to learn from past mistakes and thus, improve future programs (Alcorn et. al. 3). However, the report also shows that donors "disagree on the goals and methods of M\&E" and, furthermore, that there is no certain impact of monitoring and evaluation results on donor decision making (Alcorn et. al 3).

\subsection{Have Appropriate Monitoring and Evaluation Frameworks and Research Instruments Been Developed and Applied?}

Developing and applying evaluation frameworks and research instruments is a process that requires time and effort from the parties involved. According to my research, there is indeed a process of development and improvement of evaluation frameworks and research instruments among media NGOs and academic institutions.

As mentioned in chapter five, and in the answer to the previous question, scholars are helping media NGOs to develop frameworks and research instruments that are context specific to their sector and to conflict and post-conflict settings. However, it is difficult to say what the donors' role in this process is, more than that they are a driving force with their demands of evidence of impact. 


\subsection{Have the Caux Guiding Principles Been Established as a Type of Guidelines and if so, Are They Widely and Commonly Used?}

According to the parties interviewed, the Caux Guiding Principles are established as a type of guidelines to refer to in certain circumstances. Some organizations, like Fondation Hirondelle, have embraced them and incorporated the suggestions in their overall practice. Other organizations, for example Internews and University of Oklahoma, use them as a best practices framework, or as a reference, when designing new programs and projects.

Although the Caux Guiding Principles are used as a framework by some, it is difficult to say how widely and commonly they are used by the entire sector. From my research, it also appears that some principles are applied more often than others. For example, Principle 1, "Expand financial support for evaluation of media interventions in conflict countries", Principle 3, "Carefully select conflict-specific media indicators", and Principle 6, "Embedded evaluation into the entire project's life cycle and beyond", seem to be more commonly implemented by the organizations whom I interviewed.

\subsection{Is There a Consensus About What Indicators Are Most Appropriate to Measure Media Assistance? Is There a Common Standard Being Used?}

There is an ongoing discussion about reaching a consensus, as shown in chapters three and four. However, there is also debate about the necessity of context specific indicators and the advantages of a toolkit approach, similar to the UNESCO Indicators mentioned in chapter three. 
So far, there does not seem to be a common standard. Instead, each donor has its own specific demands of what logic models, and combinations of indicators and indices, the media NGOs should use in their applications for funding for their projects and programs. As shown in chapter three and four, even the terminology varies, as do the interpretations of this terminology. As a media NGO, independent media development consultant, or academic researcher, it is still advisable to be familiar with as many frameworks, indicators and indices as possible. In summary, it is still somewhat of a jungle out there.

\subsection{Recommendations for Future Research}

As mentioned in earlier chapters, there is not a lot of academic research on the topic of assessing media assistance, especially not in conflict and post-conflict settings. Most of the present literature is published as reports by the various media IGOs and NGOs, such as UNESCO, the World Bank, BBC Media Action, Fondation Hirondelle, Internews and IREX, or come as conference working papers or post-conference reports. It would be interesting to see some of the report findings transferred into the academic realm.

One challenge when writing this thesis was deciding what definitions of indicators to use, and what indices to include, since there is no consensus or golden standard. It would, therefore, be interesting to conduct a study of the new context-specific indicators that are developed to assess media projects in conflict and post-conflict settings, including an indexation and analysis of the various indicators and the related terminology. 
Another useful academic pursuit would be an attempt to establish a framework for how to best organize and categorize the different indices used for measuring press freedom, considering how there is no consensus on how to categorize them, and scholars and organizations within different sectors organize them differently (see my discussion in chapter two). Yet another topic would be to study the Media Map project and Media ME projects, and to compare and contrast them with the Caux Guiding Principles. I suggest that there are plenty of interesting phenomena in the media assistance sector worth exploring, especially within the conflict and post-conflict sectors. There is also a real chance for academia to share the information of these types of studies with policy makers and donors, and with an emerging community of practice eager to improve its work and prove its worth. 


\section{Appendix A}

Interview Questions

1. Why did you decide to participate in the Caux Conference?

2. What did you learn?

3. Were your expectations met? If yes, how were they met? If no, why not?

4. What impact did the Caux Conference have on the research done on monitoring and evaluation of media assistance?

5. What impact did the Caux Conference have on the collaboration of academic scholars and practitioners of media assistance and monitoring and evaluation?

6. What has happened since the conference in terms of collaboration?

7. What other projects of collaboration have you participated in?

8. Have you used the Caux Guiding Principles in your work with monitoring and evaluation?

9. As a practitioner, have you changed the process of monitoring and evaluation practice in your media assistance projects and programs? Why/why not?

10. How is monitoring and evaluation done in your organization today? Has it changed since the Caux Conference? Why/why not? Please describe. 


\section{Bibliography}

Abraham-Dowsing, Kavita, Anna Godfrey, and Zoe Khor. Reframing the Evidence Debates: A View from the Media for Development Sector. Working paper no.

7. BBC Media Action, July 2014. Web. July 2014.

Agoglia, Jon, Barbara Sotirin, and MIchael J. Dziedzic. Measuring Progress in Conflict Environments (MPICE): A Metrics Framework for Assessing Conflict Transformation and Stabilization. Washington DC: USIP, 2010. Usip.org. Web. 8 Mar. 2014.

"Aid Effectiveness - OECD." OECD. Web. 20 Mar. 2013.

Alcorn, Jason, Amy Chen, Emma Gardner, and Hiro Matsumoto. "An Overview of Current Monitoring and Evaluation Practice." (2011). Mediamapresource.org. Internews, Media Map, The World Bank. Web. 2 Mar. 2014.

Arsenault, Amelia, Sheldon Himelfarb, and Susan Abbott. Evaluating Media Interventions in Conflict Countries, Toward Developing Common Principles and a Community of Practice. Rep. Washington, D.C.: United States Institute of Peace, 2011. United States Institute of Peace. Web. 1 Oct. 2013.

Banda, Fackson. "What Are We Measuring? A Critical Review of Media Development Assessment Tools." Measures of Press Freedom and Media Contributions to Development: Evaluating the Evaluators. Vol. 4. New York: Peter Lang, 2011. 89-107. Print. Mass Communication and Journalism.

Bates, Stephen. Realigning Journalism with Democracy: The Hutchins Commission, Its Times, and Ours. Washington, D.C. (1455 Pa. Ave., N.W., Suite 200, 
Washington 20004-1008): Annenberg Washington Program, Communications Policy Studies, Northwestern U, 1995. 1-8. Print.

BBC Media Action. Online interview. 7 Apr. 2014.

Becker, L. B., T. Vlad, and N. Nusser. "An Evaluation of Press Freedom Indicators." International Communication Gazette 69.1 (2007): 5-28. Web. 12 Dec. 2013.

Bernar-Dende, Karim. Media Content in the Central African Crisis: An Overview and Solutions for Further Peace-building and Governance Interventions. Rep. Internews, May 2014. Web. June 2014.

Blue, Richard, Cynthia Clapp-Wincek, and Holly Benner. Beyond Success Stories: Evaluation For Foreign Assistance Results. Rep. USAID.gov, May 2009. Web. 12 June 2014.

Collier, David. "Insights and Pitfalls: Selection Bias in Qualitative Research." World Politics 49.1 (1996): 56-91. JSTOR. Web. 1 Oct. 2013.

"Declaration of Windhoek." Basic Texts in Communication. UNESCO. Web. 1 Oct. 2013.

"Evaluation Media's Impact in Conflict Countries." Information Packet. Caux Conference Center, Switzerland. December 2010. Email. 19 March. 2014. Fackson, Banda, and Guy Berger. How to Assess Your Media Landscape: A Toolkit Approach. Rep. Ed. Bettina Peters. Global Forum For Media Development. Web. 1 Oct. 2013.

Fondation Hirondelle. Online interview. 28 Mar. 2014.

Frohart, Mark, and Jonathan Temin. Use and Abuse of Media in Vulnerable Societies. Usip.org, Oct. 2003. Web. 3 Oct. 2014. 
Frère, Marie-Soleil. Elections and the Media in Post-conflict Africa: Votes and Voices for Peace? London: Zed, 2011. Print.

Garbarino, Sabine, and Jeremy Holland. Quantitative and Qualitative Methods in Impact Evaluation and Measuring Results. Issue brief. Governance and Social Development Resource Centre. Web. 5 Feb. 2014.

Gibaldi, Joseph. MLA Handbook for Writers of Research Papers. New York: Modern Language Association of America, 1995. Print.

Hackett, Robert A., and Richard S. Gruneau. The Missing News: Filters and Blind Spots in Canada's Press. Ottawa, ON: Canadian Centre for Policy Alternatives, 2000. 171-85j. Print.

Herman, Edward S., and Noam Chomsky. Manufacturing Consent: The Political Economy of the Mass Media. New York: Pantheon, 1988. Print.

Holtz-Bacha, Christina. "Freedom of the Press: Is a Worldwide Comparison Possible and What Is It Good For?" Measures of Press Freedom and Media Contributions to Development: Evaluating the Evaluators. Vol. 4. New York: Peter Lang, 2011. 129-44. Print. Mass Communication and Journalism.

Hume, Ellen. Media Assistance: Best Practices and Priorities, Report on a USAID Workshop. Tech. no. 4. Washington, D.C., 2003. PPC Evaluation Working Paper. Media Assistance: Best Practices and Priorities, Report on a USAID Workshop. Bureau for Policy and Program Coordination, Nov. 2003. Web. 5 Feb. 2014. 
Hyden, Goran, Michael Leslie, and FoluCommunic Folarin. Ogundimu.

"Communications and Democratization in Africa." Media and Democracy in Africa. New Brunswick, NJ: Transaction, 2002. Print.

Independent Consultant. Online interview. 19 Mar. 2014.

Internews. Online interview. 26 Mar. 2014.

IREX. Online interview. 20 Mar. 2014.

Jannusch, Sophie, ed. Measuring Change. Planning, Monitoring, Evaluation in Media Development. Rep. Forum Media and Development, Sept. 2007. Web. Apr. 2014.

Kalathil, Shanthi. "Measuring the Media: Examining the Interdisciplinary Approach." Measures of Press Freedom and Media Contributions to Development: Evaluating the Evaluators. Vol. 4. New York: Peter Lang, 2011. 271-80. Print. Mass Communication and Journalism.

King, Gary, Robert O. Keohane, and Sidney Verba. Designing Social Inquiry: Scientific Inference in Qualitative Research. Princeton, NJ: Princeton UP, 1994. Print.

Kumar, Krishna. Evaluating Democracy Assistance. Boulder, CO: Lynne Rienner, 2013. Print.

Kumar, Krishna. One Size Does Not Fit All: Objectives and Priority Areas for Media Assistance in Different Societies. Rep. Washington, D.C.: CIMA, 2009. Http://cima.ned.org/. CIMA, National Endowment for Democracy. Web. 10 Jan. 2014.

Kumar, Krishna. Promoting Independent Media: Strategies for Democracy Assistance. Boulder, CO: Lynne Rienner, 2006. Print. 
Kumar, Krishna. USAID's Media Assistance: Policy and Programmatic Lessons. Working paper no. 16. PPC Evaluation Working Paper. Usaid.gov. USAID Office of Development Evaluation and Information (DEI) Bureau for Policy and Program Coordination, Jan. 2004. Web. 5 Feb. 2014.

LaMay, Craig L. "What Works? The Problem of Program Evaluation." Measures of Press Freedom and Media Contributions to Development: Evaluating the Evaluators. Vol. 4. New York: Peter Lang, 2011. 213-38. Print. Mass Communication and Journalism.

McChesney, Robert W. "Corporate Media, Global Capitalism." Media Organization and Production. Ed. Simon Cottle. London: Sage, 2003. 27-39. Print.

McDavid, James C., and Laura R. L. Hawthorn. Program Evaluation \& Performance Measurement: An Introduction to Practice. Thousand Oaks: SAGE Publications, 2006. Print.

Media Development Indicators: A Framework for Assessing Media Development. Paris: United Nations Educational, Scientific and Cultural Organization, 2008. Print. "Media in Conflict: The Evaluation Imperative (TBC)." Draft Agenda. USIP, 9 September 2011. Email. 19 March 2014.

Mendel, Toby. Applying UNESCO's Media Development Indicators: A Practical Guide to Assist Researchers. Rep. UNESCO, Centre for Law and Democracy. Web. 5 Feb. 2014.

Mosher, Andy. "Good, But How Good? Monitoring and Evaluation of Media Assistance Projects." Measures of Press Freedom and Media Contributions to 
Development: Evaluating the Evaluators. Vol. 4. New York: Peter Lang, 2011. 239-56. Print. Mass Communication and Journalism.

Nelson, Mark, and Tara Susman-Pena. Rethinking Media Development: A Report on the Media Map Project. Rep. Internews, Media Map, The World Bank, Apr. 2012. Web. 2 Mar. 2014.

Neuman, William Lawrence. Social Research Methods: Qualitative and Quantitative Approaches. Boston: Allyn and Bacon, 1997. Print.

Oklahoma University. Online interview. 29 Mar. 2014.

Pan, Lingling, and Seung Joon Jun. "Indicators of Citizen Voice for Assessing Media Development: A Communicative Action Approach." Measures of Press Freedom and Media Contributions to Development: Evaluating the Evaluators. By Thomas Jacobson. Vol. 4. New York: Peter Lang, 2011. 281306. Print. Mass Communication and Journalism.

Power, Gerry, and Anna Godfrey. "When Theory Meets Practice: Critical Reflections from the Field on Press Freedom Indices." Measures of Press Freedom and Media Contributions to Development, Evaluating the Evaluators. By Patrick McCurdy. Vol. 4. New York: Peter Lang, 2011. 47-66. Print. Mass Communication and Journalism.

Price, Monroe E., and Mark Thompson. Forging Peace: Intervention, Human Rights, and the Management of Media Space. Bloomington: Indiana UP, 2002. Print.

Price, Monroe E., Beata Rozumilowicz, and Stefaan Verhulst. Media Reform: Democratizing the Media, Democratizing the State. London: Routledge, 2002. Print. 
Price, Monroe E. Introduction. Measures of Press Freedom and Media Contributions to Development: Evaluating the Evaluators. Vol. 4. New York: Peter Lang, 2011. 1-19. Print. Mass Communication and Journalism.

Price, Monroe E. "Restructuring the Media in Post-Conflict Societies." Cardozo Online Journal of Conflict Resolution (2000): 1-56. ProQuest. Web. 23 Mar. 2013.

Price, Monroe E., Susan Abbott, and Libby Morgan. Measures of Press Freedom and Media Contributions to Development: Evaluating the Evaluators. Vol.4. New York: Peter Lang, 2011. Print. Mass Communication and Journalism.

Puddephatt, Andrew. Defining Indicators of Media Development. Working paper. Paris: UNESCO, 2007. UNESCO. Web. 5 Feb. 2014.

Puddephatt, Andrew. "Examining and Increasing Existing Measures of Media Development." Measures of Press Freedom and Media Contributions to Development: Evaluating the Evaluators. Vol. 4. New York: Peter Lang, 2011. 67-88. Print. Mass Communication and Journalism.

Roy, Sanjukta. Overview Report: Measuring Media Development. Rep. Internews, Media Map, The World Bank, Mar. 2011. Web. 2 Mar. 2014.

Taylor, Maureen, and Susan Abbott. "Measuring the Impact of Media Assistance Programs: Perspectives on Research/Practitioner Collaboration." Measures of Press Freedom and Media Contributions to Development: Evaluating the Evaluators. Vol. 4. New York: Peter Lang, 2011. 257-67. Print. Mass Communication and Journalism. 
"The Universal Declaration of Human Rights, UDHR, Declaration of Human Rights, Human Rights Declaration, Human Rights Charter, The Un and Human Rights." UN News Center. UN. Web. 13 Aug. 2013.

Vlad, Tudor. "The Conceptualization and Operationalization of Country-Level Measures of Media Freedom." Measures of Press Freedom and Media Contributions to Development: Evaluating the Evaluators. By Lee B. Becker. Vol. 4. New York: Peter Lang, 2011. 23-46. Print. Mass Communication and Journalism. Voltmer, Katrin. Mass Media and Political Communication in New Democracies. London: Routledge, 2006. Print.

Wanchek, Natasha, and Lynn Carter. Indicator Gap Analysis. Working paper. USAID, Management Systems International, 2 Feb. 2010. Web. 12 June 2014.

World Press Freedom Index: Methodology. Rep. Reporters Without Borders. Web. 3 Apr. 2014.

Zeeuw, Jeroen De., and Krishna Kumar. "Part 3 Media." Promoting Democracy in Postconflict Societies. Boulder, CO: Lynne Rienner, 2006. 211-90. Print. 